\title{
Experimental Therapeutics for the Treatment of Osteoarthritis
}

\author{
Gundula Schulze-Tanzil \\ Department of Anatomy and Cell \\ Biology, Paracelsus Medical University, \\ Nuremberg, Bavaria, Germany
}

This article was published in the following Dove Press journal: Journal of Experimental Pharmacology
Correspondence: Gundula Schulze-Tanzil Email gundula.schulze@pmu.ac.at

\begin{abstract}
Osteoarthritis (OA) therapy remains a large challenge since no causative treatment options are so far available. Despite some main pathways contributing to OA are identified its pathogenesis is still rudimentary understood. A plethora of therapeutically promising agents are currently tested in experimental OA research to find an opportunity to reverse OA-associated joint damage and prevent its progression. Hence, this review aims to summarize novelly emerging experimental approaches for OA. Due to the diversity of strategies shown only main aspects could be summarized here including herbal medicines, nanoparticular compounds, growth factors, hormones, antibody-, cell- and extracellular vesicle (EV)-based approaches, optimized tools for joint viscosupplementation, genetic regulators such as si- or miRNAs and promising combinations. An abundant multitude of compounds obtained from plants, environmental, autologous or synthetic sources have been identified with anabolic, anti-inflammatory, -catabolic and anti-apoptotic properties. Some ubiquitous signaling pathways such as wingless and Integration site-1 (Wnt), Sirtuin, Tolllike receptor (TLR), mammalian target of rapamycin (mTOR), Nuclear Factor (NF)- $\kappa B$ and complement are involved in OA and addressed by them. Hyaluronan (HA) provided benefit in OA since many decades, and novel HA formulations have been developed now with higher HA content and long-term stability achieved by cross-linking suitable to be combined with other agents such as components from herbals or chemokines to attract regenerative cells. pH- or inflammation-sensitive nanoparticular compounds could serve as versatile slowrelease systems of active compounds, for example, miRNAs. Some light has been brought into the intimate regulatory network of small RNAs in the pathogenesis of OA which might be a novel avenue for OA therapy in future. Attraction of autologous regenerative cells by chemokines and exosome-based treatment strategies could also innovate OA therapy.
\end{abstract}

Keywords: osteoarthritis, chondrocyte, cytokine, chemokine, hyaluronan, nanoparticle, exosome, mesenchymal stromal cell, miRNA

\section{Introduction}

Osteoarthritis (OA) is the most common joint disease. It has an increasing prevalence in the more and more aging population ${ }^{1}$ and presents a large burden for the healthcare systems since it remains so far untreatable. A huge bulk of novel literature arises daily in OA research presenting a demanding challenge for OA researchers to notice the emerging innovations. In regard to therapeutical targets in OA, several reviews of literature have recently been published which can be studied. ${ }^{2-10}$ However, mesenchymal stromal cell (MSCs) or exosome-based approaches, interrelation of OA with the microbiome, novel strategies of improved viscosupplementation as well as the arising knowledge concerning the impact of micro RNAs (miRNAs) in the OA therapy are 
less addressed and hence, present a topic of this review. In view of the abundant novel literature related to these issues, this review remains mainly confined to most recent findings of the last three years. Its purpose is to discuss currently emerging experimental strategies to treat OA. It will introduce into currently known facts about the pathogenesis of $\mathrm{OA}$. Then, as research tools, the in vitro and in vivo OA models will be shortly summarized before therapeutically addressed targets and signaling pathways in OA will be presented and some promising groups of remedies will be discussed in more detail.

\section{OA Pathogenesis}

Diverse pathogenetic factors in OA have been identified including its initiation by insufficient cartilage healing after injury representing posttraumatic OA (PTOA), loss of function of cartilage during aging, ${ }^{11}$ genetic predispositions (eg, less stable cartilage ECM through mutations in ECM genes or less effective protective mediators due to mutations in their genes) or joint overload (by misalignment of leg axis or adipositas/obesity as well as meniscus damage or loss). ${ }^{12,13}$ The contribution of metabolic dysbalances (metabolic syndrome, diabetes mellitus) to OA has been underlined in the last years. ${ }^{14,15}$ Joint pain, stiffness and swelling are typical clinical features of OA. ${ }^{16}$ The progradient cartilage deterioration and subsequent loss (Figure 1) associated with OA is clinically detectable as joint space narrowing on X-ray images. Other changes include formation of osteophytes, subchondral bone sclerosis, cracks and possibly, subchondral bone marrow edema, ${ }^{17}$ as well as low-grade synovitis. ${ }^{18,19}$ OA is triggered by episodic inflammation ${ }^{1,18,19}$ and local inflammation in the affected joints which correlates with systemic inflammation markers. ${ }^{18} \mathrm{OA}$ is a whole joint disease affecting all jointassociated tissues. ${ }^{13,20,21}$
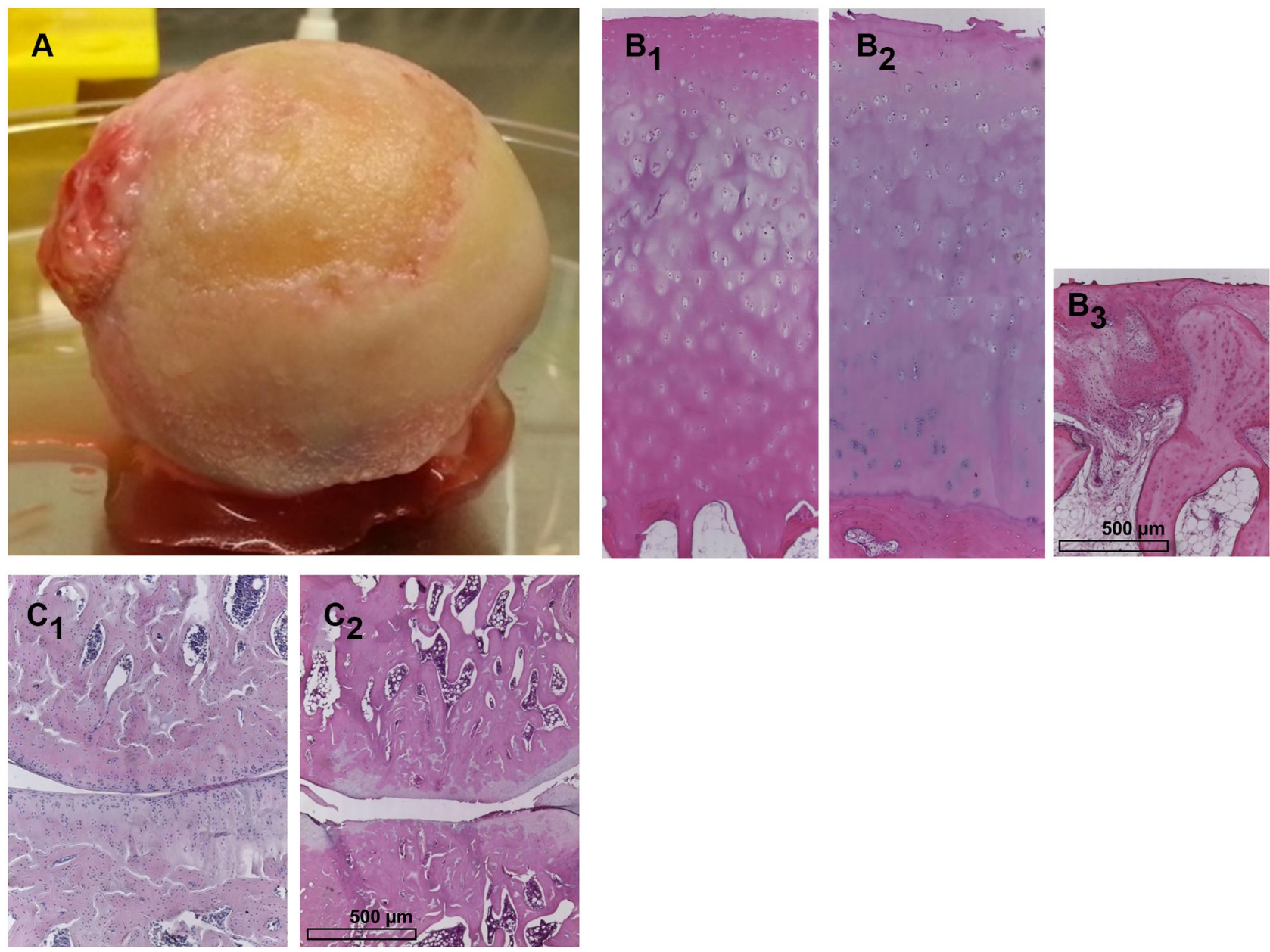

Figure I Osteoarthritic joint cartilage. (A) A femur head affected by OA explanted during joint replacement surgery is shown. Histological images (Hematoxylin Eosin staining) of (BI) nearly unaffected human cartilage, (B2 and B3) mild (hypocellularity, superficial clefts) and severely (cartilage absent, bone marrow activated, fibrosis) affected human joint cartilage. A histological image of healthy $(\mathbf{C I})$ and severely osteoarthritic $(\mathbf{C 2})$ articular cartilage of the rat knee joint. 
Typical molecular features of OA in joint cartilage are an accelerated cartilage ECM degradation enforced by a dysbalance between extracellular matrix (ECM) degrading enzymes such as matrix metalloproteinases (MMPs), a disintegrin and metalloproteinase with thrombospondin motifs (ADAMTS) and regulatory tissue inhibitors of metalloproteinases (TIMPs). ${ }^{3,22}$ Particularly the cleavage of aggrecan in cartilage is a hallmark of cartilage degeneration in $\mathrm{OA}^{22,23}$ Furthermore, ECM neosynthesis is suppressed in OA chondrocytes. ${ }^{21}$ Episodic joint inflammation is triggered by an enhanced release of proinflammatory cytokines including TNF $\alpha$, IL-1 $\beta$ and IL-6 which play a crucial role in OA. ${ }^{1,24,25}$ In addition to the aforementioned well-known cytokines increased levels of other cytokines such as IL-8 and IL-18 can also be observed. ${ }^{26}$ Cytokines are released by synovial fibroblasts (SF), macrophages or chondrocytes themselves. ${ }^{27-29}$ Chondrocytes change their cell membrane protein expression pattern comprised as surfactome in response to the presence of TNF $\alpha$ and IL- $1 \beta .^{24}$ The loss of maturational arrest of chondrocytes has been reported in $\mathrm{OA}^{30}$ leading to cell cluster formation due to uncontrolled focal cell proliferation. OA chondrocytes can undergo preterm senescence $^{30}$ or perish due to apoptosis. ${ }^{3}$ Apoptosis can arise from extrinsic, which includes death receptormediated, or intrinsic mitochondria-associated signaling pathways. Mitochondrial pathways are affected by OA reflecting oxidative stress. ${ }^{30,31}$ Mitophagy, which represents the selective uptake of mitochondria by autophagosomes of the cells, has been observed as a correlate of mitochondrial disturbances in OA. ${ }^{32,33}$ In addition, apoptosis in OA can be induced by lysosomal dysfunction as recently reported. ${ }^{34}$

Enhanced cell death and ECM degradation propagate the presence of damage products including so-called alarmins, some of them released from the cytosol. ${ }^{29}$

Alarmins which represent so-called damage-associated molecular patterns (DAMPs) are delivered as normal cellular constituents such as ECM components, S100 proteins, histones or nucleic acids ${ }^{35}$ from degraded ECM, damaged or dying cells and subsequently bind to cell membrane receptors or intracellular receptors of other cells initiating inflammatory responses. In OA an enhanced release of alarmins can be postulated. ${ }^{29}$ One receptor class binding DAMPs is the Toll-like receptor (TLR) family. ${ }^{35}$ Alarmins are involved in OA pathogenesis as recently reviewed by Minguzzi et $\mathrm{al}^{30}$. Cell and ECM fragments can also initiate complement activation ${ }^{36}$ and thereby, contribute substantially to OA pathogenesis. ${ }^{37,38}$ Despite the changes in cartilage are so far more intensively studied, the contribution of other tissues than cartilage to OA pathogenesis has to be strongly considered such as of menisci and infrapatellar fat pad (IFP)..$^{13,39,40}$ An intimate interplay between inflamed synovium and meniscus tissue of early and late OA patients could be observed in co-culture studies characterized by elevated release of inflammatory and catabolic mediators in co-cultures compared to monocultures. ${ }^{41} \mathrm{~A}$ closer focus on the IFP indicated inflammatory and fibrotic changes as well as enhanced vascularization associated with OA..$^{39,42}$ The synovial membrane and IFP might act as anatomo-functional unit involved in OA pain generation ${ }^{43,44}$ and both tissues are inflamed in OA. ${ }^{39}$ Future research should elucidate more details of the interplay of all these tissues in the scenario of OA.

\section{OA is so Far Untreatable}

There are no approved effective disease-modifying OA drugs (DMOADs) available for OA treatment. ${ }^{12}$ Only symptomatical treatment of OA can be performed. Hence, analgesics and non-steroidal anti-inflammatory drugs (NSAIDs) addressing pain and inflammation are the therapeutic options for $\mathrm{OA}^{45,46}$ with adverse effects in longterm use. ${ }^{47}$ NSAIDs are widely prescribed for the treatment of symptomatic OA of the knee. ${ }^{45}$ Therefore, the search for valuable targets requires the understanding of the interaction of different signaling pathways and has to go on remaining a challenging topic in current research. ${ }^{48}$

\section{In vitro and in vivo Disease Models for Elucidation of OA Therapeuticals}

Suitable OA models are required to decipher OA pathogenesis. Many studies are completely performed in vitro using primary chondrocytes from healthy persons or individuals suffering from OA, synovial fibroblasts (SF), several chondrocytic, synovial fibroblast (SF) or macrophage cell lines (eg, human chondrosarcoma SW1353 and OUMS-27 cell lines, murine teratocarcinoma-derived chondrocyte cell line ATDC5, SF K4IM and murine macrophage Raw 264.7 cell lines) or even cartilage explants to simulate natural three-dimensional (3D) conditions (Table 1). ${ }^{8,27,49-53}$ Cells were usually stimulated with probably mostly hyperphysiological concentrations 
Table I Examples of in vitro Models

\begin{tabular}{|c|c|c|c|}
\hline \multirow{2}{*}{\multicolumn{2}{|c|}{ Cell lines }} & \multicolumn{2}{|c|}{$\begin{array}{l}\text { Anatomic origin of main cell types } \\
\text { from the knee joint used as } \\
\text { in vitro model. } \\
\text { BM: bone marrow } \\
\text { C: cartilage } \\
\text { IFP: infrapatellar fat pad } \\
\text { M: meniscus } \\
\text { SB: subchondral bone } \\
\text { SM: synovium/synovial membrane }\end{array}$} \\
\hline & & Explants & OA induction \\
\hline $\begin{array}{l}\text { Chondrocytes (articular } \\
\text { cartilage) from unaffected or } \\
\text { OA cartilage }\end{array}$ & $\begin{array}{l}\text { OUMS- } 27,{ }^{50} \mathrm{SWI} 353^{87,88} \text { (both: human), ATDC5 }{ }^{49} \text { (mouse), fetal } \\
\text { fibroblasts immortalized with hTERT from bone+cartilage CHON- } \\
001^{89}\end{array}$ & $\begin{array}{l}\text { Cartilage }^{90} \\
\text { (unaffected or } \\
\text { OA) }\end{array}$ & \multirow{6}{*}{$\begin{array}{l}\text { Key cytokines: } \\
\text { TNF } \alpha^{87} \text { IL- I } \beta,{ }^{89} \\
\text { LPS }^{91} \\
\text { conditioned media } \\
\text { from OA cells } \\
\text { oxidative stress }^{92} \\
\text { oncostatin }^{88}\end{array}$} \\
\hline Fibrochondrocytes ${ }^{93}$ (menisci) & & Meniscus $^{41}$ & \\
\hline $\begin{array}{l}\text { Stem cells (IFP-, synovium-, } \\
\text { bone marrow-derived) }\end{array}$ & & Synovium $^{41}$ & \\
\hline Synovial fibroblasts ${ }^{27}$ & $\mathrm{~K} 4 \mathrm{IM}^{27}$ (human) & & \\
\hline Macrophages & $\begin{array}{l}\text { Raw } 264.7^{52} \text { (murine) } \\
\text { U937 } 94 \text { (human) }\end{array}$ & & \\
\hline $\begin{array}{l}\text { Osteoblasts }{ }^{95} \text { from unaffected } \\
\text { or OA subchondral bone }\end{array}$ & & $\begin{array}{l}\text { Osteochondral } \\
\text { unit }^{61}\end{array}$ & \\
\hline Adipocytes & & IFP & \\
\hline $\begin{array}{l}\text { Endothelial cells } \\
\text { (fat pad, synovium) }\end{array}$ & & & \\
\hline
\end{tabular}

Abbreviations: IFP, infrapatellar fat pad; IL, interleukin; LPS, lipopolysaccharide; OA, osteoarthritis; TNF, tumor necrosis factor.

of cytokines IL-1 $\beta$, TNF $\alpha$ or lipopolysaccharide (LPS) to simulate inflammation associated with $\mathrm{OA}^{27,28,52,54} \mathrm{On}$ first glance, LPS does not play a role in OA. However, it has recently been suggested that LPS released from the disturbed gut microbiome might provide a pathogenetic link between obesity, metabolic syndrome and OA. ${ }^{55}$ One has to consider that chondrocyte cell lines usually do not reflect all features of primary chondrocyte responses. ${ }^{50,56}$ These in vitro studies focus in the most cases only on chondrocytes and mostly neglect the interplay with other cell types in the joint such as synoviocytes (SF and macrophages), Hoffa fat pad- or subchondral bone derived-cell types. However, some co-culture models were used. Co-culture models of OA were established which consisted, eg, of cartilage and synovial membrane explants from human OA patients activated with IL-1 $\beta$ to simulate inflammation before treated with hyaluronan (HA) and
MSC-derived conditioned medium (CM) to visualize effects of this treatment approach. ${ }^{57}$ In other studies either synovium-derived MSCs and ATDC5 chondrocytes ${ }^{58}$ or human SF and articular chondrocytes were co-cultured. ${ }^{59}$ The latter study was undertaken to show the exchange of stem cell-derived extracellular vesicles (EVs) under 2D and $3 \mathrm{D}$ conditions in regard to OA. ${ }^{59}$ One should critically think about the in vitro models in regard to the fact that inflammation is refined to the presence of either TNF $\alpha$ or IL-1 $\beta$. Meanwhile it is known that other cytokines and mediators among them IL-6 or IL-18 might contribute to OA pathogenesis. ${ }^{26,41}$ In this regard studies using conditioned media from OA tissues are important. ${ }^{60}$ Most of the in vitro studies are performed in 2D culture, but there exist differences in cell behavior of 2D and 3D cultured cells. ${ }^{59}$ More sophisticated in vitro models are required, particularly more complex co-cultures including several cell 
types or tissues, eg, addressing also menisci, the osteochondral unit, synovium and the IFP of the osteoarthritic joint to reflect interactions. ${ }^{41,61}$

Several experimental settings combine in vitro analyses with preclinical in vivo models. To fully address OA as a whole joint disease, which does not exclusively affect the cartilage layer ${ }^{20}$ and to assess complex symptoms like pain in vivo models are indeed required. Preclinical OA models have already previously been thoroughly discussed and summarized. ${ }^{62,63}$ Models are performed in various animal species such as mice, rats, rabbits and dogs. ${ }^{5,62,64-66}$ Rodent models are broadly used. ${ }^{63,67-70}$ Approaches to induce OA differ (Figure 2). OA can be induced by direct damage of knee joint cartilage by application of monosodium iodoacetate (MIA model) or other harmful agents. ${ }^{71,72}$ The other models are based on creating knee instability by destabilization of the medial meniscus (DMM model) through transsection of the medial anterior meniscotibial ligament (MAMTL) which fixes the medial meniscus at the tibial plateau ${ }^{73}$ or by transsection of the medial collateral ligament (MCL) together with removal of the medial meniscus (MCL-MMx model), transsection of the medial meniscus (medial meniscus transection: MMT model) $71,73,74$, of the ACL (ACLT model $)^{75,76}$ or combinations of them. ${ }^{76}$ Novel models based on joint cartilage overloading by high impact or cyclic overloading (inducing non-invasively posttraumatic joint injury leading to posttraumatic OA [PTOA]) have also been proposed. ${ }^{68,77}$ In addition, more specific models have been described such as creating surgically patellofemoral OA by shortening the patellar ligament and thereby, changing the position of the patella and hence, its fitting accuracy in the femoropatellar groove ${ }^{78}$ or facet joint OA in the spine of rats. ${ }^{79}$ Finally, estrogen-deprivation by ovariectomy is also used ${ }^{62}$ to induce OA, being simultaneously a well-known model for osteoporosis.

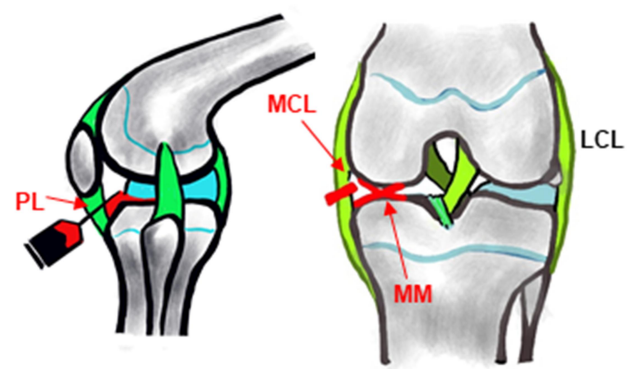

MIA
MCL-MMx

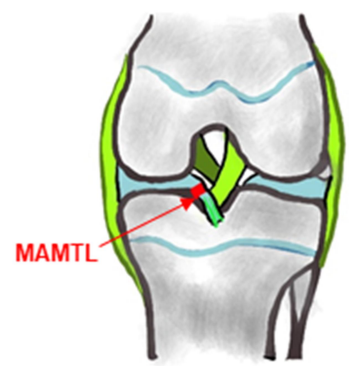

DMM

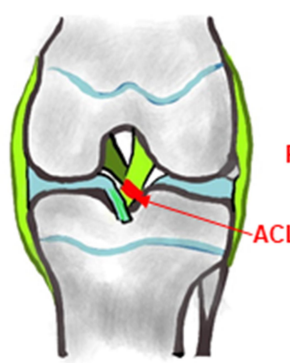

ACLT

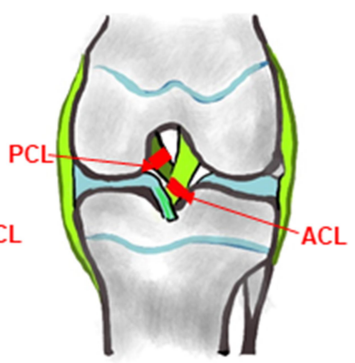

ACLT+PCLT
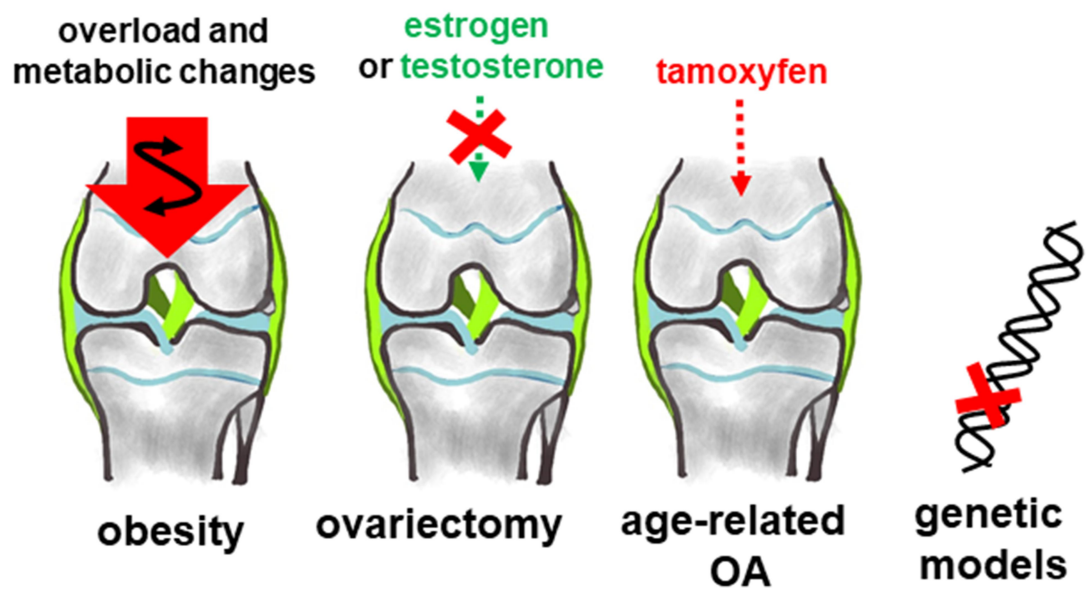

Figure 2 Most commonly used OA in vivo models. In vivo models are either established in the knee joint by application of MIA through the patellar ligament (PL) or other destructive agents (eg tamoxifen for age-related OA) which directly affect joint cartilage integrity or by creation of instability due to ligament transsection, meniscus injury or even removal. Except for MIA (sagittal) frontal views of the knee joint are depicted. OA induced by repetitive loading: by cyclic tibial compression. Joint overload by obesity. Ovariectomy impairs bone- and chondroprotective estrogen. Application of tamoxifen induces age-related OA. ${ }^{87}$ The image was created by G. Schulze-Tanzil using Krita 4.I.7 Software.

Abbreviations: MIA, monosodium iodoacetate application; MCL-MMx, medial collateral ligament (MCL) transsection and medial meniscus (MM) removal (x); DMM, destabilization of the medial meniscus by transsection of the medial anterior meniscotibial ligament (MAMTL); ACLT, anterior cruciate ligament (ACL) transsection; PCLT, posterior cruciate ligament (PCL) transsection; PTOA, post-traumatic OA; LCL, lateral collateral ligament. 
In contrast to MIA, surgical models might be more preferable reflecting more closely one crucial aspect of the natural OA pathogenesis, namely, inhomogenous joint loading by instability. ${ }^{48}$ They can display early and late OA depending on the time point of investigation selected after OA induction to perform the experiments. Aülo Rasser et al, (2020) pointed to MMT as preferable model in comparison to MIA investigating early $\mathrm{OA}^{80}$ High fat diet contributes to OA development in mice, ${ }^{81}$ hence, also obesity models exist. ${ }^{82,83}$ In addition, in mice, a couple of strains which spontaneously develop OA such as the STR/Ort mice model have been described. ${ }^{84}$ Mice models present the advantage of studying diverse gene knock outs to elucidate signaling pathways contributing to OA. ${ }^{85}$ Data from man and mice have to be brought in overlap to deduce novel therapeutic strategies in OA. Convincing concordance could be demonstrated ${ }^{48,86}$ supporting the further use of rodent models as valuable tool to improve the understanding of OA pathogenesis. Depending on the model, different compartments of the joint are affected by OA. Most studies are performed in the knee joint; however, $\mathrm{OA}$ is a heterogenous disease affecting different joints or even joint regions involving possibly diverse pathogenetic factors depending on the topographical environmental conditions. Despite cartilage is a key structure affected by $\mathrm{OA}$ and responsible for impaired joint function, other tissues impaired by OA such as menisci should be more thoroughly addressed by models. ${ }^{41}$ The limitation of in vivo models mostly performed in rodents is that it is often not possible to separate certain tissues from each other, eg, the synovial membrane from the IFP to get a simplified model to study distinct tissue-related aspects of OA pathogenesis.

One has to consider that the severity of OA and velocity of its progression differs in the various models.

\section{Therapeutically Addressed Signaling Pathways of OA}

A search for biomarkers has been undertaken to identify the early disease stages of OA. ${ }^{96}$ Chondroprotective agents effective in OA generally exert anabolic, anticatabolic-, -inflammatory, -apoptotic and mitoprotective properties. Accordingly, there exist a couple of known general approaches to address these key features.

Antagonists/inhibitors of MMPs have been tested ${ }^{97}$ to stop cartilage ECM degradation in OA. Suramin, historically used as antiparasitic and antihelminthic drug, is able to restore the expression of chondroprotective tissue inhibitor of metalloproteinase (TIMP)-3, thereby inhibiting OA cartilage degradation by MMPs. ${ }^{98}$

The direct inhibition of inflammation by neutralizing pro-inflammatory cytokines such as IL-1 $\beta$ and TNF $\alpha$ was less effective in OA. ${ }^{99}$

Anti-inflammatory cytokines could antagonize proinflammatory cytokine effects. IL-10, a member of the IL-10 family, exerts some chondroprotective effects such as inhibiting $\mathrm{TNF} \alpha$-induced apoptotic pathways in chondrocytes and partly restoring the aggrecan expression suppressed by TNF $\alpha$ in OA in vitro models. ${ }^{28,100-102}$ Hence, an agonistic IL-4/IL-10 fusion antibody seems to be promising for OA therapy. ${ }^{103}$ This therapeutical approach based on human IL-10 reduced pain in the dogs, as reported by the veterinarians and dog owners observations, without any detectable adverse effects. These results might provide a starting point for clinical trials to confirm it in future as effective. ${ }^{104}$

There is clinical evidence implicating TLRs in OA pathogenesis and $\mathrm{OA}$ associated pain, depending on disease activity as reviewed by Miller et a ${ }^{29,35}$. TLR are cell surface receptors which recognize microbial-associated molecular patterns and NFKB is a critical transcription factor for TLR downstream signaling. ${ }^{105}$ TLR2 is expressed in chondrocytes, its immunoreactivity was correlated with expression of $\mathrm{NF \kappa B}$, higher body mass index (BMI) and Western Ontario and McMaster Universities OA Index (WOMAC) scores in patients and related to OA associated changes. ${ }^{105}$ Typical ligands of TLR, which belong to the group of pattern recognition receptors are DAMPs representing ECM fragments (eg, from aggrecan, tenascin C, HA, fibronectin), S100 proteins and other factors. ${ }^{99}$ Chondrocyte apoptosis is a critical event which can be mediated by TLR signaling. ${ }^{106}$ This part of the innate immunity, the TLR mediated signaling cascades could be addressed in future in $\mathrm{OA}$ as reviewed by Barreto et $\mathrm{al}^{106}$.

Another part of the innate immune system is the complement system which is dysregulated in OA. ${ }^{38}$ It represents a cascade of components activated by proteolytic cleavage. Split fragments are released during activation. The important anaphylatoxins $\mathrm{C} 3 \mathrm{a}$ and $\mathrm{C} 5 \mathrm{a}$ result from the cleavage of the components $\mathrm{C} 3$ and $\mathrm{C} 5$ and bind to cellular receptors (eg, $\mathrm{C} 3 \mathrm{aR}$ and $\mathrm{C} 5 \mathrm{aR}$ ) initiating inflammatory responses. The finally arising complement complex at the end of the cascade, the membrane attack complex, forms pores after integrating into target cell membranes, thereby 
leading to cell lysis. ${ }^{107}$ Accordingly, the expression of inflammatory and degradative molecules was lower in chondrocytes from destabilized joints of complement C5deficient mice than $\mathrm{C} 5$-sufficient mice. Activation of complement is abnormally high in human osteoarthritic joints. ${ }^{38}$ Due to the involvement of complement activation in OA, complement inhibitors could serve as promising agents in future OA therapy. ${ }^{37,38}$

The sirtuin (SIRT) signaling pathway (SIRT)/p53 axis has strongly been implicated in $\mathrm{OA}^{86}$ Sirtuins and Forkhead box O (FoxOs), the latter a target of sirtuins have chondroprotective properties. SIRT1 is known to exert anti-apoptotic effects. The FoxO signaling pathway is one of the most dysregulated pathways in human OA cartilage compared to normal tissue, but SIRT1 might not be exclusively beneficial. ${ }^{108,109}$ Melatonin, a hormone regulating circadian rhythm released from the pineal gland, is known to inhibit the SIRT1 pathway and possesses chondroprotective effects. ${ }^{110,111}$

The mammalian target of rapamycin (mTOR) signaling pathway, initiated by mTOR as a critical serin/threonine protein kinase, plays a crucial role for chondrocyte homeostasis and its dysbalance contributes to OA associated joint degeneration. Inhibition of this pathway and mTOR knock outs lead to reduction of the severity of OA in mouse models as reviewed recently. ${ }^{112-114}$

The reactive oxygen species (ROS)/extracellular signal regulated kinase (ERK)/Nuclear factor (erythroid-derived 2)like 2 (Nrf2) signaling pathways have been implicated in OA. ${ }^{115}$

Adenosine monophosphate-activated protein kinase (AMPK) activation - a cell energy sensor, ${ }^{116,117}$ acting via SIRT3, limits oxidative stress and improves mitochondrial DNA integrity and function in OA chondrocytes. These effects likely contribute to chondroprotective effects of AMPK activity. ${ }^{31}$

The wingless and integration site-1 (Wnt) pathway is strongly implicated in OA. Signaling molecules and regulators of Wnt are abnormally activated or suppressed under OA conditions. Hence, agonists and antagonists of this pathway have attracted interest for future OA treatment as reviewed previously. ${ }^{48,118}$ First attempts have been undertaken to modulate this pathway: inhibition of the Wnt/beta-catenin signaling with the compound lorecivivint prevented cartilage degradation and impaired pain in a preclinical model of posttraumatic OA (PTOA) probably via reduced signal transducer and activator of transcription (STAT) signaling. Lorecivivint has already entered Phase I and Phase 2 trials, reducing pain and joint narrowing. ${ }^{119}$

The Runt related transcription factor (RUNX) 2 regulates osteoblast and chondrocyte differentiation and was induced in murine OA models underlining an involvement in OA development. Hence, it has been postulated as a potential novel target for therapeutical intervention. ${ }^{120}$

The observation that the transmembrane protein aquaporin (AQP)-1, responsible for water transport was upregulated in OA cartilage initiated more detailed investigations which showed that this surface protein facilitated caspase- 3 activation promoting chondrocyte apoptosis as a typical feature of OA. ${ }^{121}$

In addition, it has been shown that PTEN-induced kinase (Pink)1 mediated chondrocytic mitophagy, initiated chondrocyte death and contributed thereby, to cartilage degeneration in OA. ${ }^{122}$ Not only Pink1 but also Parkin proteins were increased in OA. ${ }^{123}$ The Parkin protein might protect from ROS accumulation mediating chondrocyte survival. ${ }^{124}$

One shared target of several above-mentioned signaling pathways is the NF- $\mathrm{KB}$ signaling. ${ }^{125}$ However, NF- $\mathrm{\kappa B}$ is involved in many pathways mediating anabolic and catabolic processes in cartilage. ${ }^{125}$ This transcription factor is inhibited by many potential agents of OA (Table 2) including herbal medicines.

The endocannabinoid-associated signaling pathway is involved in pain regulation in OA. ${ }^{126}$

\section{Herbal Medicines and Dietary Phytochemicals (Nutraceuticals)}

Herbal medicines and other compounds from natural resources, eg, uptaken as nutraceuticals represent an emerging field in OA therapy and novel candidates have been summarized in several very recent reviews. ${ }^{8,9,127}$ Some agents have been used empirically since centuries, eg, in Chinese traditional medicine (see Table 2). ${ }^{128}$ More systematical screening has been undertaken to identify novel promising compounds ${ }^{129}$ and chemoinformatic recherche exploring suitable compounds based on their putative properties deduced from chemical structure and composition was also applied to identify valuable agents for OA. ${ }^{8}$ Nutrigenomics is an additional strategy to find potential therapeutics tailored for individual patients. ${ }^{130}$ This novel field implicates that nutrients affect the expression of an individual's gene setting, translation of proteins and arising metabolites or protect its genes from damage. ${ }^{131}$ A problem of natural compounds is the fact to be extracted from herbals or other environmental sources. The content of active compounds is influenced by extraction and 
Table 2 Synopsis of Some Compounds Extracted from Natural Resources

\begin{tabular}{|c|c|c|}
\hline Compound & Effects/Models Used & Reference \\
\hline Artemisinin & 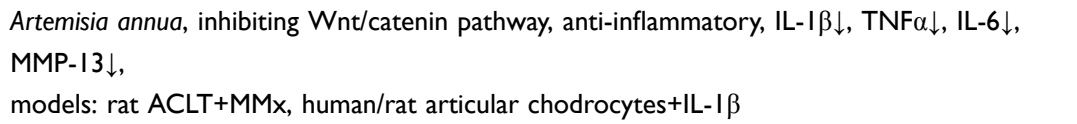 & {$[76]$} \\
\hline Berberine & $\begin{array}{l}\text { Rhizoma coptidis, protein kinase B (AKT) signaling, NO } \downarrow \text {, inhibited PG, ACAN and collagen } \\
\text { degradation by IL-I } \beta, \rightarrow \text { cartilage degeneration } \downarrow \\
\text { models: rat articular chondrocytes }+I L-I \beta, A C L T+M M x\end{array}$ & [133] \\
\hline Blue mussel water extract & $\begin{array}{l}\text { Mytilus edulis, pro-inflammatory mediators } \downarrow \text { oxidative stress } \downarrow \text {, cartilage degradation } \downarrow \text { and pain } \downarrow \text {, } \\
\text { anti-obesity effect in obese OA rats, NF- } \mathrm{B} B \text { inhibition could be hypothesized } \\
\text { model: rat ACLT+MMx (high fat diet obese rats) }\end{array}$ & {$[75]$} \\
\hline Butein & 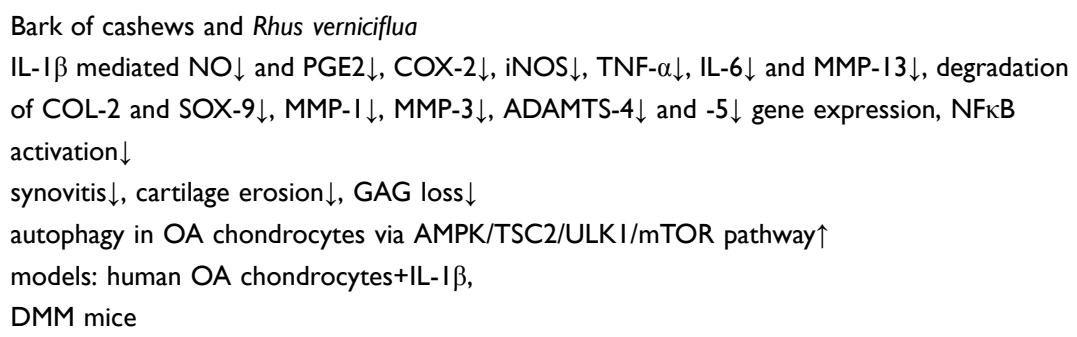 & {$[134,135]$} \\
\hline Carnosol & $\begin{array}{l}\text { Rosemary, MMP-3 } \downarrow \text {, IL- } 6 \downarrow, \mathrm{NO} \downarrow, \text { ADAMTS- } 4 \downarrow \text {, collagen type II } \uparrow \\
\text { models: human osteoarthritic chondrocytes, co-cultured with sclerotic or non-sclerotic } \\
\text { osteoblasts }\end{array}$ & {$[95,136]$} \\
\hline Centella asiatica, Boswellia serrata & $\begin{array}{l}\text { Centella asiatica and Boswellia serrata, NO } \downarrow \text {, iNOS } \downarrow \text { (in vitro in macrophages), pain } \downarrow \\
\text { models: MIA and RAW } 264.7 \text { macrophages }\end{array}$ & {$[52]$} \\
\hline Curcumin & $\begin{array}{l}\text { Curcuma longa, AKT/mTOR, pain } \downarrow \text {, inhibits NF- } \mathrm{KB} \text {, restored type II collagen, autophagy } \\
\text { capacity. Apoptosis } \downarrow, \text { MMP- } 3 \downarrow \\
\text { models: chondrocytes (human, mice and rat articular chondrocytes }+\mathrm{IL}-\mathrm{I} \beta \text { or oxidative stress), } \\
\text { spontaneous OA mice model, DMM mice model, aging related OA mice model via tamoxifen } \\
\text { administration }\end{array}$ & {$[92,137-139$} \\
\hline Comarum palustre $\mathrm{L}$. & $\begin{array}{l}\text { Traditional medicine drug, TNF } \alpha \downarrow \text {, IL-10个, adiponectin } \uparrow \text { in patients, pain } \downarrow \text {, disability } \downarrow \text {, OA } \\
\text { symptoms } \downarrow \\
\text { model: human patients }\end{array}$ & {$[140]$} \\
\hline Daphnetin & 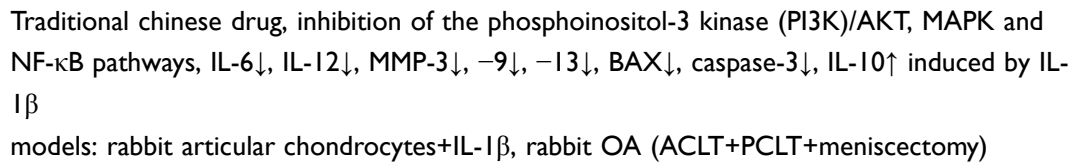 & {$[|4|]$} \\
\hline Dehydrocostus lactone & $\begin{array}{l}\text { Medicinal plants, NF- } \mathrm{KB} \text { inhibition, inhibited oxidative stress: ROS } \downarrow, \mathrm{IL}-I \beta \downarrow \text {, IL- } 6 \downarrow \text {, restored } \\
\text { collagen type II and ACAN, MMPs+ADAMTS } \downarrow \text { by TNF } \alpha \\
\text { model: SWI } 353 \text { chondrocytes }+\mathrm{TNF} \alpha\end{array}$ & {$[87]$} \\
\hline $\begin{array}{l}\text { Grape seed oil, in combination } \\
\text { with avocado }\end{array}$ & $\begin{array}{l}\text { Grape seed oil, cartilage degradation } \downarrow \text {, inhibits loss of chondrocytes, PGs, osteophytes } \downarrow \text {, } \\
\text { ROS } \downarrow \text {, MMP-3, }-\mid 3 \downarrow \text {, nitrotyrosine } \downarrow \text {, and IL-I } \beta \downarrow \\
\text { model: ACLT rat }\end{array}$ & [142] \\
\hline Green tea polyphenols, theanine & $\begin{array}{l}\text { L-theanine, Epigallocatechin 3-gallate (=polyphenol), pro-inflammatory mediators } \downarrow \text {, COX- } 2 \downarrow \text {, } \\
\text { PGE2 } \downarrow \text {, iNOS } \downarrow, N O \downarrow \text {, diverse MMPs } \downarrow, \text { ADAMTS } \downarrow \text {, MMP regulator CITED2, IL-I } \downarrow \downarrow \text {, TNF } \alpha \downarrow \text {, } \\
\text { chemokine receptor (CCR)2 } \downarrow \text {, NF-kB inhibition (p65 activation } \downarrow \text { ), OA lesions } \downarrow \text { (in vivo and } \\
\text { in vitro) } \\
\text { models: rat chondrocytes+IL-I } \beta, \text { ACLT rats, DMM mice }\end{array}$ & {$[9,143,144]$} \\
\hline
\end{tabular}

(Continued) 
Table 2 (Continued).

\begin{tabular}{|c|c|c|}
\hline Compound & Effects/Models Used & Reference \\
\hline Harpagophytum procumbens & $\begin{array}{l}\text { Harpagophytum procumbens extract, MMP-I } \downarrow,-3 \downarrow,-9 \downarrow \text { induced by IL-I } \beta \text {, cannabinoid receptor } \\
\text { (CBR) } 2 \uparrow, \text { pain } \downarrow \text {, probably via NF-KB and endocannabinoid system } \\
\text { model: articular chondrocytes }+\mathrm{IL}-\mathrm{I} \beta \text { (human) }\end{array}$ & {$[145]$} \\
\hline Icariin & $\begin{array}{l}\text { Extract of Epimedium, NOD-, LRR- and pyrin domain-containing protein (NLRP)3/caspase-I } \\
\text { signaling mediated pyroptosis in OA } \\
\text { models: rat articular chondrocytes+LPS, MIA rat }\end{array}$ & {$[146]$} \\
\hline Isoliquiritigenin & $\begin{array}{l}\text { Licorice flavonoids, progression of OA } \downarrow \text {, bone resorption } \downarrow \text { and angiogenesis } \downarrow \text { in subchondral } \\
\text { bone, MMP- } 2 \downarrow \text {, Receptor Activator of NF- } \mathrm{kB} \text { Ligand (RANKL)-RANK-TNF receptor } \\
\text { associated factor (TRAF) } 6 \text { signaling } \\
\text { model: ACLT mice }\end{array}$ & {$[147]$} \\
\hline Kaempferol & 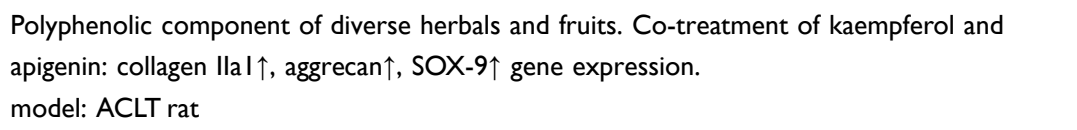 & {$[148,149]$} \\
\hline $\begin{array}{l}\text { Krill oil mixture with astaxanthin } \\
\text { and } \mathrm{HA}\end{array}$ & 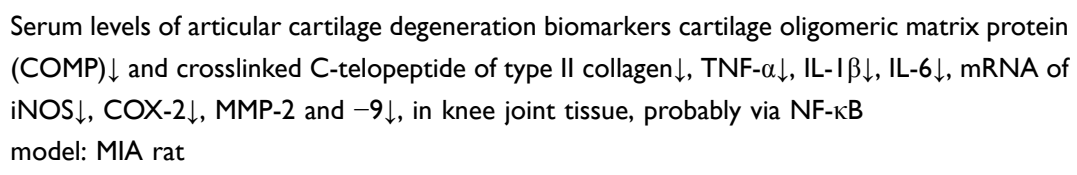 & {$[150]$} \\
\hline Olive-derived polyphenols & $\begin{array}{l}\text { Olive, contains polyphenols: including hydroxytyrosol, tyrosol, oleocanthal and oleuropein } \\
\text { anti-inflammatory, with antioxidant and autophagy-enhancing activities (via SIRTI) } \\
\text { models: rabbit articular cartilage defect, human trials }\end{array}$ & {$[151]$} \\
\hline $\begin{array}{l}\text { Paeonia (P.) lactiflora and the } \\
\text { gum resin of } C \text {. myrrha }\end{array}$ & $\begin{array}{l}\text { Traditional medicines, P. lactiflora root and C. myrrha gum resin, NO } \downarrow \text {, iNOS } \downarrow \text {, IL-I } \downarrow \downarrow \text {, IL-6 } \downarrow \text {, } \\
\text { COX- } 2 \downarrow \text {, cartilage erosion and subchondral bone damage } \downarrow \\
\text { model: MIA rat }\end{array}$ & {$[128]$} \\
\hline Phyllanthus emblica & $\begin{array}{l}\text { Fruit extract, hyaluronidase and collagenase } 2 \text { activity } \downarrow \text {, chondroprotection } \\
\text { model: human OA articular cartilage explants }\end{array}$ & [90] \\
\hline Quercetin & $\begin{array}{l}\text { Achyranthes bidentata, (Quercetin, baicalein, and berberine are contained), inhibitors of TNF } \alpha \\
\text { and IL- } 6 \text { signaling, and tumor suppressor protein (TP) } 53 \text {, inflammation } \downarrow \text {, apoptosis } \downarrow \\
\text { model: rat chondrocytes+IL-I } \beta\end{array}$ & [129] \\
\hline Resveratrol & 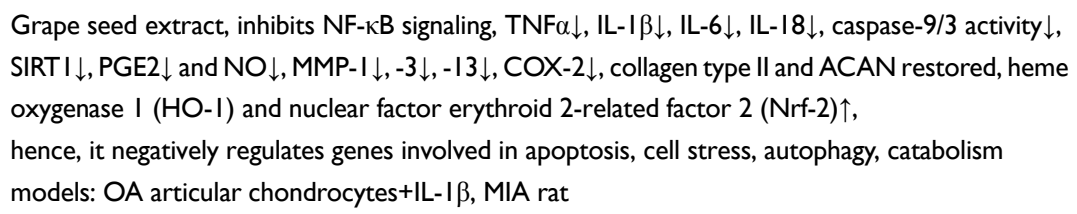 & {$[152,153]$} \\
\hline Stinging nettle & $\begin{array}{l}\text { Stinging nettle, MMP-I } \downarrow, \text { MMP- } 3 \downarrow, \text { MMP-9 } \downarrow \\
\text { Hypothesized: inhibits NF- } \kappa B \text { signaling } \\
\text { model: human articular chondrocytes+IL- } \mid \beta\end{array}$ & {$[154]$} \\
\hline Sulforaphane & $\begin{array}{l}\text { Vegetables, broccoli-derived isothiocyanate, regulates Nuclear factor (erythroid-derived)-like (Nrf2) } \\
\text { and histone deacetylase activity, cytokine-induced MMP expression } \downarrow \text {, inhibits NF- } \kappa B \text { signaling } \\
\text { models: SWI353, human articular chondrocytes+IL-I } \beta \text { and oncostatin, bovine nasal cartilage } \\
\text { explants, DMM mice }\end{array}$ & {$[88]$} \\
\hline Tanshinone & $\begin{array}{l}\text { Traditional Chinese medicine Danshen, progression of OA } \downarrow \text {, synovitis } \downarrow \text {, restores collagen type II } \\
\text { and aggrecan, apoptosis } \downarrow \text {, MMP- } \mid 3 \downarrow \text {, ECM degradation } \downarrow \text { induced by IL- I } \beta \text {, probably via NF-kB } \\
\text { models: CHON-00I fetal fibroblasts from bone and cartilage, immortalized with hTERT+IL-I } \beta \text {, } \\
\text { ACLT mice }\end{array}$ & [89] \\
\hline
\end{tabular}

(Continued) 
Table 2 (Continued).

\begin{tabular}{|c|c|c|}
\hline Compound & Effects/Models Used & Reference \\
\hline Trans-capsaicin & $\begin{array}{l}\text { Chili peppers, improved pain with walking, knee stiffness, and physical function in OA patients } \\
\text { with knee pain, Phase II study } \\
\text { model: human patients }\end{array}$ & [6] \\
\hline Thymoquinone & $\begin{array}{l}\text { Nigella sativa, immunomodulatory, anti-inflammatory and anti-oxidant properties, IL- } 4 \uparrow \text {, IL- } 10 \uparrow \text {, } \\
\text { survivin } \uparrow, \text { Bax } \downarrow \text {, cytokine levels: IFN- } \gamma \text {, TNF- } \alpha \text {, COX-2, IL-6, IL-8, IL-I2A and IL-I6 depended } \\
\text { on concentrations of thymoquinone, regulation of canonical pathways directly related to } \\
\text { synaptogenesis, neuroinflammation, TGF- } \beta \text {, and interleukin signaling was predicted in silico } \\
\text { model: human bone marrow MSCs and in silico analysis }\end{array}$ & {$[155]$} \\
\hline Ursolic acid & 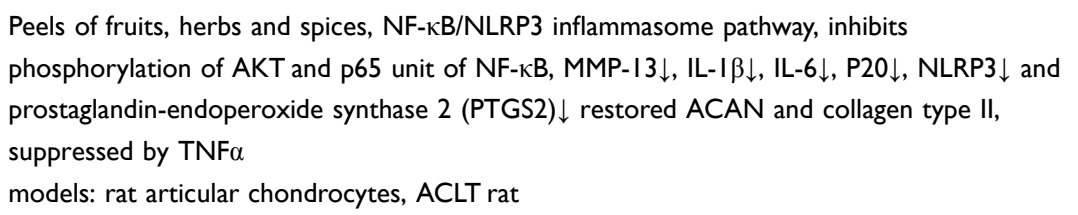 & {$[156]$} \\
\hline Verbascoside & $\begin{array}{l}\text { Eg in olives, pro-inflammatory cytokines } \downarrow \text {, targeting purinergic type } 2 \text { receptor (P2X7R) } \\
\text { expression, production of MMPs, PGE2, NF-KB signaling pathway } \downarrow \\
\text { model: MIA rats }\end{array}$ & {$[25]$} \\
\hline Wogonin & $\begin{array}{l}\text { Root extract of Scutellaria baicalensis, IL- } 6 \downarrow, \text { COX- } 2 \downarrow, \text { PGE } 2 \downarrow \text {, iNOS } \downarrow \text { and NO } \downarrow \text {, disrupts kelch- } \\
\text { like ECH associated protein (KEAP)-I/Nrf- } 2 \text { interaction } \\
\text { models: human OA articular chondrocytes+IL-I } \beta \text {, DMM mice }\end{array}$ & {$[115,157]$} \\
\hline Yellow oil of Zingiber montanum & $\begin{array}{l}\text { Zingiber montanum } \\
\text { pain } \downarrow \text { inhibition of COX and lipoxygenase (LOX) pathways, possibly via NF- } \mathrm{KB} \downarrow \\
\text { model: human patients }\end{array}$ & {$[45]$} \\
\hline
\end{tabular}

Abbreviations: ACAN, aggrecan; ACLT, anterior cruciate ligament transsection; ADAMTS, a disintegrin and metalloproteinase with thrombospondin motifs; AKT, protein kinase B; BAX, Bcl-2 associated protein X; CBR, cannabinoid receptor; CITED2, Cbp/P300 Interacting Transactivator With Glu/Asp Rich Carboxy-Terminal Domain 2; COX, cyclooxygenase; DMM, destabilized medial meniscus; ECM, extracellular matrix; IFN, interferon; IL, interleukin; iNOS, inducible nitric oxide synthase; KEAP, kelch-like ECHassociated protein; LOX, lipoxygenase; MAPK, MAP kinase; MIA, monosodium iodoacetate application; MMP, matrix metalloproteinase; MMx, medial meniscus removal; mTOR, mammalian target of rapamycin; NLRP3, NOD-, LRR- and pyrin domain-containing protein 3; NO, nitric oxide; Nrf2, Nuclear factor (erythroid-derived 2)-like 2; OA, ostoarthritis; PCLT, posterior cruciate ligament transsection; PG, proteoglycans; PGE, prostaglandin E; PI3K, phosphoinositol-3 kinase; PTGS2, prostaglandin-endoperoxide synthase 2; P2X7R, purinergic type 2 receptor; RANK(L), Receptor Activator of NF- $K B$ (Ligand); ROS, reactive oxygen species; SIRT, Sirtuin; TRAF, TNF receptor associated factor; TP53, tumor suppressor protein 53; Wnt, wingless and Integration site-I.

purification strategies, local growth conditions of plants (eg, soil composition) and further, the often used oral application route which is associated with inhomogeneous intake and limited possibly, inconsistent bioavailability. ${ }^{132}$ On the contrary, one has also to consider that compounds when systemically uptaken have to pass the blood-joint barrier consisting of the connective tissue between synovial capillaries and synoviocytes cell layers. The density of this barrier changes due to synovitis associated with OA.

\section{Novel Synthetic Compounds as Candidates for OA Treatment: Nanoparticular Compounds and Antibodies}

Candidate therapeutics for OA treatment are selected based on the current understanding of its molecular pathogenesis. ${ }^{3}$
Various nanoparticular compounds have been developed with putative implication in OA treatment. ${ }^{10}$ Nanoparticular compounds such as dendritic polyglycerol sulfates (dPGS) could act as anti-inflammatory agents in $\mathrm{OA}^{74,100,158,159}$ A challenge for nanoparticular compounds is to penetrate the cartilage ECM for internalization by articular chondrocytes as key player cell population in OA which depends on their size, loading and binding motifs allowing receptor interaction for uptake into target cells. ${ }^{100,159}$ Particles with high affinity to the targets or even inflamed tissues are of particular interest. ${ }^{159}$ Such compounds could act locally in the joint despite of being administered systemically impairing the overall risk of adverse effects adherent with this class of compounds.

Nanoparticles could also present a versatile slow release system and be combined with other agents. Rhein- 
loaded pH-responsive nanoparticles have been developed. ${ }^{160} \mathrm{pH}$ responsiveness of loaded nanoparticles allows accumulation or even the release of the effective agent in inflamed tissue which are usually characterized by lower $\mathrm{pH}$ values. ${ }^{160}$ Rhein has approved anti-inflammatory capacity. ${ }^{132,160}$ Nanoparticles were also used to deliver siRNA of $66 \mathrm{kDa}$ proto-oncogene Src homologouscollagen homologue (p66shc) which is involved in cartilage degeneration in $\mathrm{OA}$ and known to mediate oxidative stress-induced apoptosis. ${ }^{161}$ By delivering p66shc-siRNAloaded Poly(lactide-co-glycolide) (PLGA) nanoparticles into the osteoarthritic knee joints, mitochondrial dysfunction-induced cartilage damage was significantly impaired suggesting them as an option for the treatment of OA. ${ }^{122}$

In addition to being effective, nanoparticles should be highly cytocompatible, or capable to be easily eliminated, eg, by self-degradation to disappear, and not to accumulate and produce unwanted adverse effects.

In addition to nanoparticles, other therapeutical compounds have been investigated such as the $\mathrm{H}_{2} \mathrm{~S}$-producing enzyme 3-mercaptopyruvate sulfurtransferase (3-MST) which could be loaded in future on nanoparticles. $\mathrm{H}_{2}$ $\mathrm{S}$ generated by 3-MST protects against joint calcification and experimental $\mathrm{OA}$ progression. Hence, enhancing $\mathrm{H}_{2}$ $\mathrm{S}$ production in chondrocytes may represent a potential disease modifier to treat OA. ${ }^{162}$ Other compounds belong to the group of bisphosphonates such as tiludronate, which impaired pain, joint effusion, synovitis, MMP-13 and ADAMTS expression in OA knees of dogs suggesting efficacy in OA. ${ }^{163}$

To directly neutralize harmful mediators upregulated in OA such as pro-inflammatory cytokine antibody therapy presents a strategy. Some antibody-based approaches have been developed. Antibody-based anti-cytokine therapy was effective in rheumatoid arthritis (RA) but bears also risks such as immunosuppression and malignancies. ${ }^{164}$ However, anti-cytokine therapy like in RA was less effective in OA. ${ }^{48}$ Antibodies against pro-inflammatory mediators including IL-1 $\beta$ and TNF $\alpha$ have failed in recent OA clinical trials as reviewed by Mimpen and Snelling. ${ }^{6}$ Other options to utilize antibodies have been tested in OA such as anti-ADAMTS-5 monoclonal antibodies as a tool to directly inhibit aggrecanase in OA. ${ }^{22}$ Increased vascularization of the synovial membrane but also vessels penetrating into cartilage can be observed in OA and both are associated with increased vascular endothelial growth factor (VEGF) activity. Bortezomib, a vascular endothelial growth factor receptor 3 (VEGFR3) neutralizing antibody reduced joint tissue damage in a mouse model of experimental PTOA, which was associated with improved synovial lymphatic function. ${ }^{165}$

Antibody-based complement inhibitors could be interesting as OA therapeutics. ${ }^{36-38,166}$ Unfortunately, so far not enough is known about the role of distinct complement components in OA. ${ }^{37}$

However, therapeutical antibodies have to be stable enough to be administered and one has to consider that this therapy is indeed expensive.

\section{Anabolic Factors: Growth Factors and Hormones, Hormone Analogues}

The insufficiency of chondrocytes to respond to different growth factors has been implicated in OA pathogenesis. ${ }^{167}$ The anabolic growth factor insulin-like growth factor (IGF)-1 is important to maintain cartilage ECM homeostasis. The decreased levels of IGF-1 may play a critical role for the loss of the balance between catabolic and anabolic processes in cartilage metabolism during the development of OA. Thus, increasing IGF-1 may be applicable to restore homeostasis and as an approach in future OA therapy. ${ }^{168}$

The anabolic growth factor fibroblast growth factor (FGF) 18 acts chondroprotective via regulating TIMP-1 expression and hence, inhibiting ECM degradation. ${ }^{48,169}$

The female sex hormone estrogen is known to have chondroprotective effects. ${ }^{170}$ Accordingly, estrogen deprivation by ovariectomy is used as OA model. ${ }^{62}$ A lack in estrogen explains the high predisposition of postmenopausal woman for OA. ${ }^{170}$ Genistein is the major active component of isoflavone, with a chemical composition and a biological effect that is very similar to that of estrogens, which prevents the degradation of articular cartilage. ${ }^{171}$

Glucagon is an anabolic hormone regulating carbohydrate metabolism. The glucagon-like peptide-1 receptor (GLP-1R) leads to anti-inflammatory and anti-apoptotic effects in cartilage. Activating GLP-1R suppressed the $\mathrm{NF}-\kappa \mathrm{B}$ pathway, decreased the release of proinflammatory key mediators (TNF $\alpha$, IL-6), and reduced ECM catabolism in triglyceride-treated chondrocytes. These effects were reversed by GLP-1R knockdown. ${ }^{172,173}$

Melatonin is an epiphyseal hormone strongly associated with the circadian rhythm. Melatonin was able to impair IL-1 $\beta$-induced MMP production by inhibiting SIRT1-dependent pathways in chondrocytes, suggesting melatonin as a potential therapeutic candidate in OA. ${ }^{110}$ 
Recently the putative involvement of melatonin, the hypophyseal hormone thyroid stimulating hormone (TSH), and suprarenal gland-derived cortisol have been implicated in OA pathogenesis with respect to influencing the circadian clock as reviewed by Hossain et al. ${ }^{111}$ which opens a novel perspective on the multifaceted nature of $\mathrm{OA}$ pathogenesis.

The hormone oxytocin (OT) induced increased aggrecan, collagen type $\mathrm{X}$, and COMP levels in vitro, and a normalization of cartilage markers such as SRY-box transcription factor 9 (SOX9) and collagen type II. There was a significant correlation between OA and impaired OT in rats. OT stimulated chondrogenesis. Systemic OT levels in the serum were also impaired in human patients with hand OA. This suggests that OT might be involved in the pathophysiology of OA. ${ }^{174}$

The hormone prolactin and its cleavage products, the vasoinhibins, can be implicated in regulation of angiogenesis in OA. Prolactin could be a candidate for OA therapy. ${ }^{37}$

Pain is the main symptom in OA impairing patient's life quality. Nerve growth factor (NGF) sensitizes pain sensory nerve fibers; hence, inhibition of its signaling pathway could modulate pain sensation. ${ }^{48}$

Irisin represents a myokine which has also effects on cartilage. It is a cleaved form of fibronectin type III domain containing 5 (FNDC5), and normally regulates bone turnover and muscle homeostasis. A study revealed that human osteoarthritic articular chondrocytes express decreased level of FNDC5 and the autophagosome marker light chain (LC) 3-II, but upregulated levels of the oxidative DNA damage marker 8-hydroxydeoxyguanosine and apoptosis. Irisin repressed inflammation-mediated oxidative stress and ECM underproduction through retaining mitochondrial biogenesis, dynamics and autophagic program. ${ }^{175}$

Recently, the small molecule kartogenin regulating the core binding factor subunit (CBF) $\beta$-RUNX1 pathway was reported to promote the differentiation of bone marrow (BM)-derived MSCs (BM-MSCs) into chondrocytes in vitro. Kartogenin exhibited chondroprotection when injected i.a. in two mouse models of OA. ${ }^{176}$

\section{A more comprehensive understanding of OA: influence of the microbiome}

A more comprehensive image of OA becomes visible showing that $\mathrm{OA}$ is to some degree indeed a systemic disease since systemic hormone and factor disbalances are involved in its pathogenesis as outlined before and also systemic cytokine levels are substantially changed in OA. ${ }^{18}$ The gut-associated microbiome contributes also to OA. In this regard a microbiome-joint connection has been postulated by Favazzo et $\mathrm{al}^{177}$. A dysbiosis of the gut microbial flora might trigger the systemic release of potentially harmful bacterial components which could affect the homeostasis of the joints making them more susceptible for OA development or progression. LPS might accumulate in response to microbiome imbalance (dysbiosis) and present a link by mediating low-grade inflammation between obesity and metabolic syndrome. ${ }^{55}$ In this regard, the biotransformation of curcumin, for example, by gut microbiota might explain its beneficial health effects ${ }^{138}$ and this important mechanism might also influence other compounds. Therefore, this interrelation has to be addressed in more detail in future.

\section{Cell-Based Approaches in OA: MSCs}

There exist already results from several clinical trials using MSCs in OA. ${ }^{178,179}$ MSCs have various protective effects which might be mediated by trophic mediators released by MSCs (Figure 3). Different MSC species can be applied either allogenic or autologous. Adipose tissue-derived mesenchymal stromal cells (ASCs) have the advantage of easy and less invasive accessibility by liposuction. ${ }^{179}$ Intraarticular application (i.a.) of autologous ASCs without culturing them inhibited the progression of cartilage degeneration ${ }^{180}$ but also allogenic ASCs expanded by culturing attenuated cartilage degeneration in an experimental rat OA model. ${ }^{181}$ Allogenic BM-MSCs were expanded under hypoxic conditions before injected in combination with HA into rat knees in a rat ACLT model leading to superior results compared to controls and revealing that an engraftment of MSCs into joint cartilage takes indeed place. ${ }^{182}$

In contrast to these promising results, i.a. injection of xenogenic SF-MSCs did neither exert chondroprotection nor does it impair inflammation in ACLT-induced OA in the rat knee. ${ }^{183}$

Encouraging were the results with allogenic amniotic MSCs which impaired OA progression in a synovial macrophage-mediated in vitro cartilage explant co-culture model. ${ }^{184}$

The adipose tissue-derived stromal vascular fraction (SVF) represents a potent precursor cell population which can be harvested from adipose tissue. ${ }^{179}$ SVFs have been tested as promising healing approach in OA. ${ }^{17,185}$ SVF fraction acts 


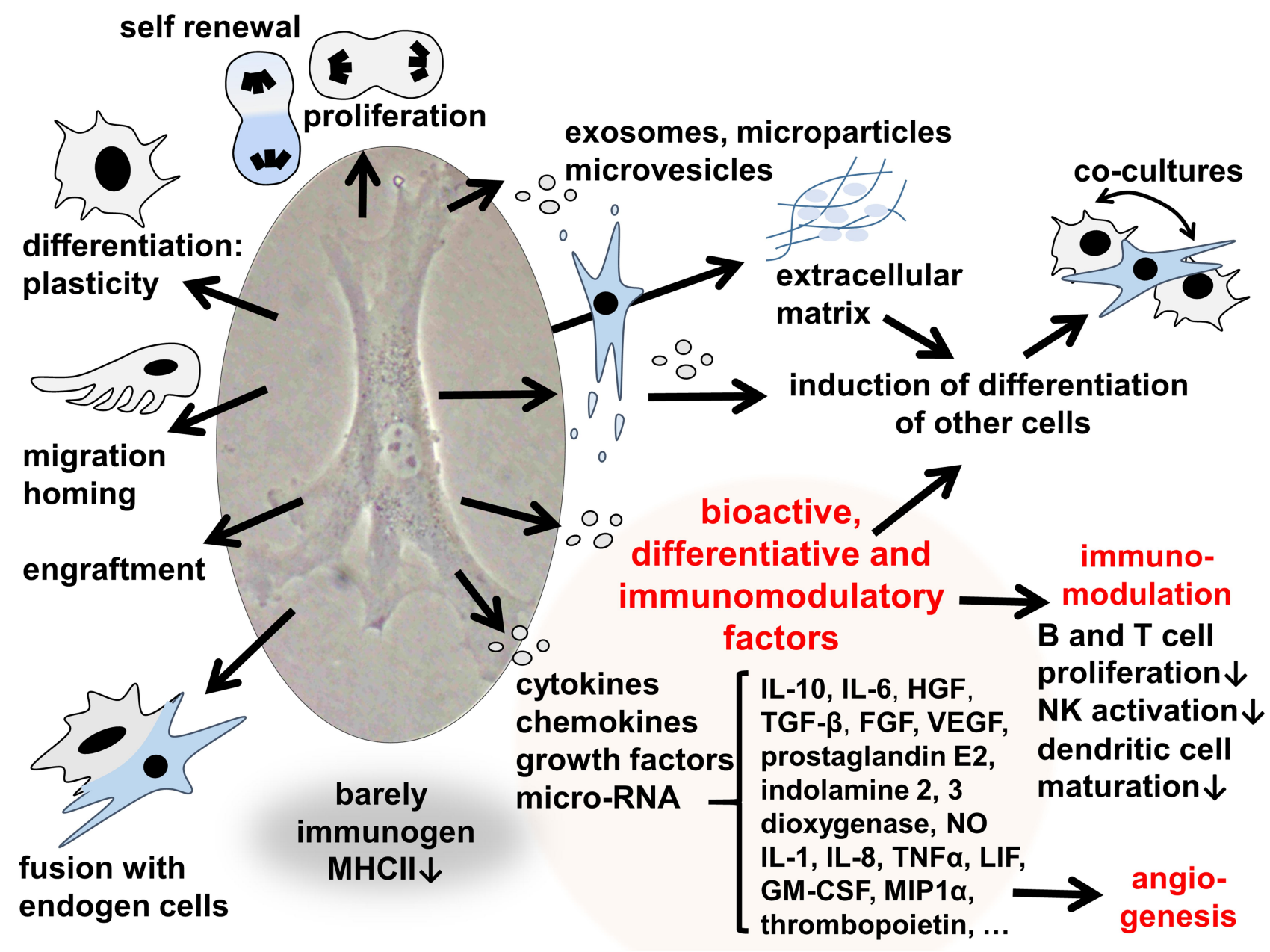

Figure 3 Capacities which could stimulate cartilage healing exerted by mesenchymal stromal cells. The image was created by G. Schulze-Tanzil.

Abbreviations: FGF, fibroblast growth factor; GM-CSF, granulocyte-macrophage colony-stimulating factor; HGF, hepatocyte growth factor; IL, interleukin; LIF, leukemia inhibitory factor; MHCII, major histocompatibility complex II; MIPI $\alpha$, macrophage inflammatory protein; NK, natural killer cells; NO, nitric oxide; TGF, transforming growth factor; VEGF, vascular endothelial growth factor.

anti-inflammatory in temporomandibular joint OA. ${ }^{186}$ It was concluded that the i.a. application of SVFs to treat knee OA was safe and chondroprotective for the tested time period of 1 year. SVFs might induce a cascade of molecular and structural responses mediated through complex interactions between infrapatellar fat pad fatty tissue and SVFs, and enforcing the intraarticular fatty tissue back to homeostasis, protective, and anti-inflammatory functions, as an explanation for the inhibition of OA progression observed. ${ }^{185}$

\section{Chemokines}

Chemokines are able to attract regenerative stem cells. The application of chemokines might be less invasive compared to preparing and injecting stem cells. The term of in situ tissue engineering was postulated to describe this strategy to support cartilage defect healing. ${ }^{187}$ There are some hints indicating that chemokine signaling might be disturbed in OA. The CXC-motif-chemokine receptor (CXCR) 4 which has probably chondroprotective capacities was downregulated by miR-146a in chondrocytes under inflammatory conditions. Its overexpression attenuated inflammation. ${ }^{49}$ A comprehensive transcriptome analysis of OA versus non-OA samples with clinical data integration reflected that many chemokine genes were significantly downregulated under OA conditions. ${ }^{188}$ On the contrary, the chemokine IL- 8 (CXC motif chemokine [CXCL]8) was increased in synovial fluid and plasma of OA patients ${ }^{26}$ and the chemokine CXCL1 contributed to pro-inflammatory IL-6 expression in OA SF mediated by the CXC-motif-chemokine receptor 2, rapidly accelerated fibrosarcoma (c-Raf), MAPK, and activator protein (AP)-1 signaling pathways. ${ }^{188,189}$ Hence, the intimate interplay between chemokine subtypes and other key pathways has to be further addressed in future. 


\section{Platelet-Rich Plasma}

Platelet-rich plasma (PRP) contains growth factors and diverse mediators such as cytokines and chemokines. It is used for stem cell culturing and to promote tissue regeneration. The study of Mariani et al, $2020^{51}$ in SF summarizes reference data on the concentration and release kinetics of biomolecules that could represent potential specific effectors in the modulation of inflammatory processes and in tissue repair after treatment with PRP. Another research team reported that PRP combined with alendronate delayed OA progression by inhibiting the NF- $\mathrm{KB}$ signaling pathway. ${ }^{190}$

\section{Conditioned Media}

Chemokines, cytokines, growth factors are released by chondrogenic cells during culturing mediating paracrinic signaling. Conditioned media (CM) harvested from cultured cells contain these diverse products of cells. Since $\mathrm{CM}$ can influence cell differentiation they have also been tested in OA models as therapeutical option. CM from notochordal cells, which represent embryonic precursor cells found as leftovers in the immature intervertebral disc cartilage, revealed protective effects in OA. ${ }^{191} \mathrm{CM}$ of ASCs was also used for cartilage stimulation and found to be a promising treatment strategy for $\mathrm{OA}$ in experimental models. ${ }^{57} \mathrm{CM}$ contained also socalled exosomes harboring the above-mentioned mediators.

\section{Extracellular Vesicles: Microvesicles and Exosomes}

Exosomes and microvesicles are extracellular vesicles (EV), surrounded by a phospholipid membrane either cell membrane- or endosomal-derived, of different sizes (30-$100 \mathrm{~nm}$ or $0.1-1 \mu \mathrm{m})$. EVs are released by diverse cell types including those of the joint. EVs mediate paracrinic cell-cell communication, being produced by cell membrane budding of donor cells and are internalized by recipient cells including joint-derived cells such as chondrocytes and SF. ${ }^{54,59,192}$ An uptake of ASC-derived EVs by SF and chondrocytes could be observed in in vitro co-culture models of SF and chondrocytes from the same OA patient which differed under 2D and 3D conditions. Interestingly, SFs showed a faster uptake of EVs than chondrocytes. $^{59}$

BM-MSC-derived EVs can prevent OA-associated catabolic features simulated by IL-1 $\beta$ exposure by reinduction of cartilage ECM marker gene expression such as collagen type II alpha 2 chain (COL2A1) and aggrecan (ACAN), inhibition of MMP and ADAMTS (MMP-13 and ADAMTS-5) gene expression, suppression of pro-inflammatory mediators such as NO production, apoptosis and macrophage activation, thereby modulating immune reactivity as shown in chondrocytes in vitro. ${ }^{54,192}$

Chondrocyte proliferation and migration capacity were also restored by EVs in vitro. ${ }^{54}$ Using the rat MIA OA model, exosome treatment significantly reconstituted collagen type II and impaired MMP-13 protein expression in the knee joint cartilage of the OA rats. ${ }^{54}$

ASCs are easier to harvest compared to BM-MSCs. Nevertheless, also ASC-derived EVs are effective in modulating features associated with OA. Activated SF treated with exosomes suppressed their expression of pro-inflammatory mediators such as IL-6, NF- $\mathrm{BB}$ and TNF $\alpha$, while the expression of anti-inflammatory IL-10 was elevated. ${ }^{193}$ Exosomes can be used clinically, ${ }^{194}$ being harvested by sequential centrifugation techniques from cultured MSCs before i.a. injected. ${ }^{192}$ The immunogenicity of EVs, since they expose membrane proteins on their surface, remains unclear, and hence, the necessity to isolate them from autologous cell populations. Nevertheless, EVs can also be isolated from autologous plasma or serum. ${ }^{195}$ The treatment of chondrocytes with EVs isolated from autologous blood products (hyperactive serum and citrate-anticoagulated PRP) induced the expression of anabolic markers such as the chondrogenic transcription factor SOX9, type II collagen and aggrecan, compared to the original complete full blood products, but it induced also the ECM degradative MMP-3. The blood product-derived EVs but not the blood product itself increased SOX9 protein expression and inhibited IL-6 release in human chondrocytes from OA patients. ${ }^{195}$

The content of EVs depends on diverse factors, such as cell source, culturing time and conditions and this might explain some heterogenicity of results studying the effect of EVs and their perspective for OA. ${ }^{91,196,197}$ In addition to diverse proteins, lipids, cytokines and chemokines, they contain also mRNA or miRNA. ${ }^{198}$ However, contents depend largely on the methods of purification. An important question to be answered in future concerns whether these particles are able to penetrate the cartilage ECM. 


\section{Restorage of Joint Function by Viscosupplementation and Restored Osmolarity}

Viscosupplementation implies the application of natural components of cartilage ECM and synovial fluid to restore its viscoelastic properties and provide lubrication of joint cartilage surface to reduce friction. HA is most important for this unique properties of the synovial fluid. In a healthy joint, it has a content of 2-4 mg/mL HA with an MW of 4-6 MDa. ${ }^{199}$ Hence, viscosupplementation is mostly based on application of HA which represents a well-established OA therapy, ${ }^{200}$ but other compounds such as glucosamine are also proposed. ${ }^{201,202} \mathrm{HA}$ is a natural non-sulfated high molecular weight (MW) glycosaminoglycan (GAG) ${ }^{203}$ with broad medical application. ${ }^{53}$ In OA, the content of HA in the synovial fluid is reduced which, hence, loses its viscoelasticity/thixotropic properties ${ }^{203}$ and is not any longer able to impair friction during joint movement. It gets a lower MW during aging. ${ }^{203}$ $\mathrm{HA}$ is responsible to maintain aggrecan aggregates of sufficient sizes in the cartilage ECM. ${ }^{204}$ It exerts anti-inflammatory, apoptotic, -catabolic, -nociceptive and anabolic effects. ${ }^{205-207}$ HA binding to chondrocytes is mediated by the HA receptor,
CD44. ${ }^{204}$ The full mechanism of action of exogenous HA is uncertain, but studies indicate that it may promote endogenous HA production, reduce joint inflammation, prevent degeneration of cartilage and facilitate its healing. ${ }^{208}$

However, there exist diverse variants of $\mathrm{HA}^{203}$ possessing different MWs. ${ }^{209}$ High MW would provide longer lasting protective effects in OA-affected joints. ${ }^{210}$ The capacity of HA to penetrate the cartilage ECM and directly modulate chondrocyte activity remains a matter of debate. A drawback of HA therapy is the preferred i.a. application route. Multiple HA injections are recommended to achieve effects of sufficient duration. ${ }^{211}$ Hence, in regard to the necessity of multiple i.a. injection which bears the risk of joint infection longterm stability of HA is desired which can be achieved by cross-linking, eg, represented by Hylan G-F. ${ }^{202,212}$ HA, but also chondroitin sulfate as another effective GAGs for viscosupplementation, have extensively been tested in rat OA models. ${ }^{69}$ Chondroitin sulfate has been used for years to ameliorate $\mathrm{OA}$ as reviewed in detail by Mimpen and Snelling. ${ }^{6,69}$ Another compound used since many years for viscosupplementation in OA is glucosamine, an aminosugar of the natural cartilage ECM. ${ }^{213}$

Lubricin (also called proteoglycan 4 [Prg4]) is naturally produced by superficial zone articular chondrocytes

Table 3 Some miRNAs with Implication in OA Restricted to 2018-2020

\begin{tabular}{|c|c|c|}
\hline Type & Implication & Reference \\
\hline $\operatorname{miR}-140$ & Promoting cartilage formation $\uparrow$, inhibiting degeneration $\downarrow$, role in chondrogenesis (MSCs) & {$[227]$} \\
\hline miR-23b-3p & Promotes ECM degradation by activating P38 MAPK in chondrocytes and OA cartilage & {$[228]$} \\
\hline $\begin{array}{l}\text { IncRNA } \\
\text { HOTAIR }\end{array}$ & $\begin{array}{l}\text { Silencing inhibited } \mathrm{Wnt} / \beta \text {-catenin pathway, declined synovial inflammation and synoviocyte proliferation, and } \\
\text { promoted apoptosis in OA rats }\end{array}$ & [229] \\
\hline miR-103a-3p & $\begin{array}{l}\text { Upregulation: cell proliferation } \uparrow \text {, apoptosis } \downarrow \text {, inflammation } \downarrow \text {, caspase- } 3 \downarrow \text {, Poly(ADP-ribose)-Polymerase (PARP) } \downarrow \text {, } \\
\text { IL- I } \beta \downarrow \text {, IL- } 6 \downarrow \text {, IL- } 10 \downarrow \text { and TNF- } \alpha \downarrow \text {. High mobility group box I (HMGBI), an inflammatory mediator of OA, is } \\
\text { a target of miR-I03a-3p }\end{array}$ & {$[230]$} \\
\hline $\begin{array}{l}\operatorname{miR}-145 \text { and } \\
\text { miR-22I }\end{array}$ & $\begin{array}{l}\text { Upregulation of miR-I45 and miR-22I: proliferation of periosteal cells } \uparrow \text { and chondrogenic potential } \uparrow . \text { Evidence in } \\
\text { support for the use of patient-derived exosomes (from ASCs), for potential amelioration of OA }\end{array}$ & {$[193]$} \\
\hline miR-136-5p & $\begin{array}{l}\text { BM-MSC-derived exosomal miR- I36-5p: chondrocyte migration } \uparrow \text { in vitro and cartilage degeneration } \downarrow \text { in vivo, OA } \\
\text { pathology } \downarrow\end{array}$ & {$[231]$} \\
\hline $\operatorname{miR}-495$ & $\begin{array}{l}\text { CircSERPINE2 could mediate TGFBR2 expression by binding with miR- } 495 \text {. As a conclusion, CircSERPINE2 } \\
\text { attenuated IL-I } \beta \text {-caused apoptosis and ECM degradation of chondrocytes by regulating miR-495/TGFBR } 2 \text { axis } \rightarrow \\
\text { new target for OA treatment. }\end{array}$ & {$[232]$} \\
\hline miR-17-5p & OA cartilage and IL-I $\beta$-induced chondrocytes: miR-I7-5p $\downarrow$ Fucosyltransferase (FUT)I $\uparrow$ & {$[233]$} \\
\hline miR-296-3p & $\begin{array}{l}\text { CircCDHI } 3 \text { contributes to OA pathogenesis by acting as a sponge of miR-296-3p and regulating the miR-296-3p- } \\
\text { PTEN pathway. Silencing of CircCDHI3: chondrocyte apoptosis } \downarrow \text {, ECM catabolism } \downarrow \text {, anabolism } \uparrow \text {, in vivo: } \\
\text { alleviated OA. }\end{array}$ & {$[234]$} \\
\hline
\end{tabular}

Abbreviations: ASC, adipose tissue-derived mesenchymal stromal cells; FUT, Fucosyltransferase; HMGBI, High mobility group box I; i.a., intraarticular; MAPK, MAP kinase; miR, microRNA; PARP, Poly(ADP-ribose)-Polymerase; TGFBR2, Transforming growth factor $\beta$ receptor 2; Wnt, wingless and integration site-I. 
and SF in the joint and important for cartilage lubrication to minimize friction during movements within the joint. Gene therapy by inducing overexpression of the Prg4 gene in the joint was protective in OA. ${ }^{214,215}$ Gene therapy was also performed by combination of $\operatorname{Prg} 4$ and interleukin receptor antagonist (IL-1ra) genes which protected against hyperalgesia and cartilage degeneration in the PTOA model. ${ }^{216}$ The receptor antagonist transgene was also tested locally in an equine $\mathrm{OA}$ joint model leading to substantial increase in IL-1ra mediating reduced lameness, lesser joint pathology revealed by imaging, alleviated synovitis and improved healing of osteochondral lesions whereas no systemic increase in IL-1ra was observed. ${ }^{217}$

Adaption of dysbalanced osmolarity could present a future strategy in OA therapy. Osmolarity intimately regulates growth factor expression. ${ }^{218,219}$ Decreased osmolarity contributes to sustained inflammation and catabolic activities in OA chondrocytes and impairs their responsiveness to the growth and differentiation factor (GDF)-5. This suggests that osmolarity represents a critical factor in $\mathrm{OA}$ pathogenesis ${ }^{220}$ and should be further addressed. HA is often combined with other therapeutical agents, ${ }^{221} \mathrm{eg}$, cells ${ }^{222}$ or chemokines. ${ }^{223}$

\section{Genetic Regulators of Inflammatory/Catabolic Gene Expression}

Genetic and epigenetic regulation has been implicated in OA pathogenesis. ${ }^{224} \mathrm{OA}$-associated epigenetic aberrations have been recognized at the level of DNA methylation and histone modification in chondrocytes. ${ }^{225}$ DNA methylation is known to destinate gene expression as reviewed by Kim et al. ${ }^{226}$

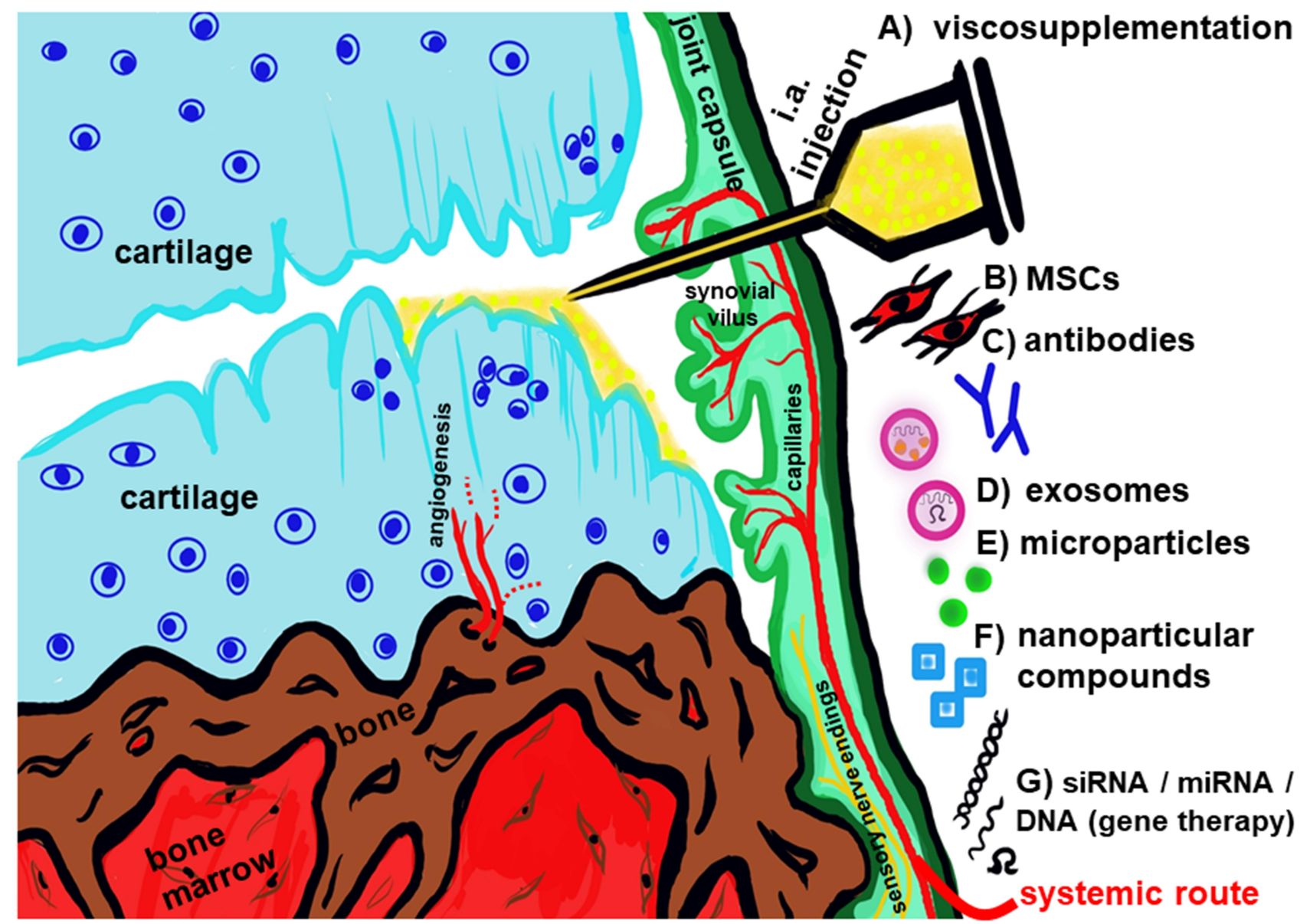

Figure 4 Synopsis of some current experimental therapeutic strategies in OA. (A) viscosupplementation such as i.a. application of HA to improve gliding properties of damaged cartilage as well as stimulate regenerative capacity of chondrocytes. (B) application of MSCs with immunomodulatory and trophic properties. (C) administering antibodies to inhibit inflammatory pathways in the joint. (D) provide exosomes as vehicles for chondroprotective cellular products. (E) apply microparticles. (F) give nanoparticular compounds with anti-inflammatory properties. (G) apply inhibitory and regulatory small RNA or DNA interfering with inflammatory pathways in the joint. Abbreviation: i.a., intraarticular; miRNA, micro ribonucleic acid; MSC, mesenchymal stromal cells; siRNA, small interfering ribonucleic acid. The image was created by G. Schulze-Tanzil using Krita 4.1.7 software. 
Micro RNAs (miR) are important regulators of gene expression. They represent a class of regulatory but noncoding RNAs (around 22 nucleotides in length). Despite the knowledge about their regulatory network is still limited a growing number of miRs has been implicated in OA pathogenesis based on their aberrant expression profiles under OA conditions (Table 3). miRs and small interfering RNAs (siRNAs) could present future tools in OA therapy being, eg, combined with nanoparticles, microvesicles or other carriers. ${ }^{122,193}$ Limitations to be addressed in future could be to maintain stability and achieve sufficient high local concentrations of therapeutical miRNAs.

\section{Conclusion}

It has to be considered that $\mathrm{OA}$ is a systemic and generally heterogenous disease. ${ }^{7,46}$ Many players (growth factors, diverse hormone networks, circadian clock factors, gut microbiome, nutrigenomics, epigenetics: eg miRs ...) and several dysregulated signaling pathways are involved in its pathogenesis which might differ dependent on individual patients. NF- $\mathrm{KB}$ dysregulation seems to play a major role. There exist meanwhile various novel or further optimized experimental strategies to alleviate $\mathrm{OA}$ progression (Figure 4). Approaches for treatment have possibly to be adapted in future to disease subtypes and individual patients. Hence, personalized OA therapy should be a future vision.

\section{Abbreviations}

ACAN, aggrecan gene; ACL, anterior cruciate ligament; ACLT, anterior cruciate ligament transsection; ADAMTS, a disintegrin and metalloproteinase with thrombospondin motifs; AKT, protein kinase B; AMPK, Adenosine monophosphate-activated protein kinase; AP-1, activator protein1; ASCs, adipose tissue-derived mesenchymal stromal cells; Aqp, aquaporin; BM, bone marrow; BM-MSCs, bone marrow-derived mesenchymal stromal cells; BMI, body mass index; $\mathrm{CBF} \beta$, core binding factor subunit $\beta ; \mathrm{CM}$, conditioned media; COL2A1, gene for alpha1 chain of collagen type II; COMP, cartilage oligomeric matrix protein; COX, cyclooxygenase; CXCR4, CXC-motif-chemokine receptor 4; DMM, destabilized medial meniscus; dPGS, dendritic polyglycerol sulfates; ECM, extracellular matrix; ERK, extracellular signal regulated kinase; EV, extracellular vesicles; FGF, Fibroblast growth factor; FNDC5, fibronectin type III domain containing 5; FoxOs, Forkhead box O; FUT1, Fucosyltransferase 1; GAG, glycosaminoglycans; GDF, growth and differentiation factor; GLP-1R, glucagon- like peptide-1 receptor; GM-CSF, granulocyte-macrophage colony stimulating factor; HA, hyaluronan; HGF, hepatocyte growth factor; IPF, intrapatellar fat pad; IL, interleukin; IL-1ra, interleukin-1 receptor antagonist; iNOS, inducible nitric oxide synthethase; IGF-1, insulin-like growth factor1; KEAP, Kelch-like ECH-associated protein; LCL, lateral collateral ligament; LIF, leukemia inhibitory factor; LPS, lipopolysaccharide; MAMTL, medial anterior meniscotibial ligament; MAPK, MAP kinase; MCL, medial collateral ligament; MHCII, major histocompatibility complex II; MIA, monosodium iodoacetate; MIP1 $\alpha$, macrophage inflammatory protein; miRNA, micro ribonucleic acid; MMP, matrix metalloproteinase; MMT, medial meniscus transsection; 3-MST, 3-mercaptopyruvate sulfurtransferase; mTOR, mammalian target of rapamycin; MW, molecular weight; NGF, nerve growth factor; NLRP3, NOD-, LRRand pyrin domain-containing protein 3 ; NK, natural killer cells; NO, nitric oxide; Nrf, Nuclear factor (erythroidderived)-like; OA, osteoarthritis; OT, oxytocin; PARP, Poly(ADP-ribose)-Polymerase; PCL, posterior cruciate ligament; PG, proteoglycan; PGE, Prostaglandin E; Pink1, PTEN induced kinase 1; PI3K, phosphoinositol-3 kinase; PRP, platelet-rich plasma; PTGS2, prostaglandinendoperoxide synthase 2; PTOA, posttraumatic OA; P66shc, $66 \mathrm{kDa}$ proto-oncogene Src homologous-collagen homologue; RANK(L), Receptor Activator of NF- $\mathrm{KB}$ (Ligand); Raf, rapidly accelerated fibrosarcoma; ROS, reactive oxygen species; RUNX, runt related transcription factor; SF, synovial fibroblasts; SIRT, sirtuin; siRNA, small interfering ribonucleic acid; SOX9, SRY-box transcription factor 9; SVF, stromal vascular fraction; STAT, signal transducer and activator of transcription; TGF, transforming growth factor; TLR, Toll like receptor; TIMP, tissue inhibitors of metalloproteinases; TNF, tumor necrosis factor; TRAF, TNF receptor associated factor; TSH, thyroid stimulating hormone; VEGF, vascular endothelial growth factor; VEGFR3, vascular endothelial growth factor receptor 3; Wnt, wingless and integration site-1; WOMAC, Western Ontario and McMaster Universities Osteoarthritis Index.

\section{Acknowledgment}

The author would like to thank Mr. Benjamin Kohl for support.

\section{Disclosure}

The author reports no conflicts of interest in this work neither financial nor other. 


\section{References}

1. Chow YY, Chin KY. The role of inflammation in the pathogenesis of osteoarthritis. Mediators Inflam. 2020;2020:8293921. doi:10. $1155 / 2020 / 8293921$

2. Goldring MB, Berenbaum F. Emerging targets in osteoarthritis therapy. Curr Opin Pharmacol. 2015;22:51-63. doi:10.1016/j. coph.2015.03.004

3. Kim JR, Yoo JJ, Kim HA. Therapeutics in osteoarthritis based on an understanding of its molecular pathogenesis. Int $\mathrm{J} \mathrm{Mol} \mathrm{Sci.}$ 2018;19.

4. Watt FE, Gulati M. New drug treatments for osteoarthritis: what is on the horizon? Eur Med J Rheumatol. 2017;2:50-58.

5. Masson AO, Krawetz RJ. Understanding cartilage protection in OA and injury: a spectrum of possibilities. BMC Musculoskelet Dis. 2020;21:432. doi:10.1186/s12891-020-03363-6

6. Mimpen JY, Snelling SJB. Chondroprotective factors in osteoarthritis: a joint affair. Curr Rheumatol Rep. 2019;21:41. doi:10. 1007/s11926-019-0840-y

7. Van Spil WE, Kubassova O, Boesen M, Bay-Jensen AC, Mobasheri A. Osteoarthritis phenotypes and novel therapeutic targets. Biochem Pharmacol. 2019;165:41-48. doi:10.1016/j. bcp.2019.02.037

8. Li XZ, Zhang SN. Recent advance in treatment of osteoarthritis by bioactive components from herbal medicine. Chin Med. 2020;15:80. doi:10.1186/s13020-020-00363-5

9. Leong DJ, Choudhury M, Hirsh DM, Hardin JA, Cobelli NJ, Sun HB. Nutraceuticals: potential for chondroprotection and molecular targeting of osteoarthritis. Int J Mol Sci. 2013; 14:23063-23085. doi:10.3390/ijms141123063

10. Jin GZ. Current nanoparticle-based technologies for osteoarthritis therapy. Nanomaterials. 2020;10:2368. doi:10.3390/nano10122368

11. Loeser RF, Collins JA, Diekman BO. Ageing and the pathogenesis of osteoarthritis. Nat Rev Rheumatol. 2016;12:412-420. doi:10.1038/nrrheum.2016.65

12. He Y, Li Z, Alexander PG, et al. Pathogenesis of osteoarthritis: risk factors, regulatory pathways in chondrocytes, and experimental models. Biology. 2020;9:194. doi:10.3390/biology90 80194

13. Edd SN, Giori NJ, Andriacchi TP. The role of inflammation in the initiation of osteoarthritis after meniscal damage. $J$ Biomech. 2015;48:1420-1426. doi:10.1016/j.jbiomech.2015.02.035

14. Schwarz S, Mrosewski I, Silawal S, Schulze-Tanzil G. The interrelation of osteoarthritis and diabetes mellitus: considering the potential role of interleukin-10 and in vitro models for further analysis. Inflam Res. 2018;67:285-300. doi:10.1007/s00011-017-1121-8

15. Tchetina EV, Markova GA, Sharapova EP. Insulin resistance in osteoarthritis: similar mechanisms to type 2 diabetes mellitus. J Nutr Metabol. 2020;2020:4143802. doi:10.1155/2020/4143802

16. Roman-Blas JA, Bizzi E, Largo R, Migliore A, HerreroBeaumont G. An update on the up and coming therapies to treat osteoarthritis, a multifaceted disease. Exp Opin Pharmacother. 2016;17:1745-1756. doi:10.1080/14656566. 2016.1201070

17. Tran TDX, Wu CM, Dubey NK, et al. Time- and Kellgren(-) lawrence grade-dependent changes in intra-articularly transplanted stromal vascular fraction in osteoarthritic patients. Cells. 2019;8:308. doi:10.3390/cells8040308

18. Babaei M, Javadian Y, Narimani H, et al. Correlation between systemic markers of inflammation and local synovitis in knee osteoarthritis. Caspian J Int Med. 2019;10:383-387.

19. Mathiessen A, Conaghan PG. Synovitis in osteoarthritis: current understanding with therapeutic implications. Arthritis Res Ther. 2017;19:18. doi:10.1186/s13075-017-1229-9
20. Loeser RF, Goldring SR, Scanzello CR, Goldring MB. Osteoarthritis: a disease of the joint as an organ. Arthritis Rheum. 2012;64:1697-1707. doi:10.1002/art.34453

21. Schulze-Tanzil G. Intraarticular ligament degeneration is interrelated with cartilage and bone destruction in osteoarthritis. Cells. 2019;8:990. doi:10.3390/cells8090990

22. Apte SS. Anti-ADAMTS5 monoclonal antibodies: implications for aggrecanase inhibition in osteoarthritis. Biochem J. 2016;473: e1-e4. doi:10.1042/BJ20151072

23. Mort JS, Geng Y, Fisher WD, Roughley PJ. Aggrecan heterogeneity in articular cartilage from patients with osteoarthritis. $B M C$ Musculoskelet Dis. 2016;17:89. doi:10.1186/s12891-016-0944-8

24. Jeremiasse B, Matta C, Fellows CR, et al. Alterations in the chondrocyte surfaceome in response to pro-inflammatory cytokines. BMC Molecular Cell Biol. 2020;21:47. doi:10.1186/ s12860-020-00288-9

25. Ma H, Qin S, Zhao S. Osteoarthritis is prevented in rats by verbascoside via nuclear factor kappa B (NF-kappaB) pathway downregulation. Medical Sci Monit. 2020;26:e921276. doi:10. 12659/MSM.921276

26. Koh SM, Chan CK, Teo SH, et al. Elevated plasma and synovial fluid interleukin- 8 and interleukin- 18 may be associated with the pathogenesis of knee osteoarthritis. Knee. 2020;27:26-35. doi:10.1016/j.knee.2019.10.028

27. Mrosewski I, Jork N, Gorte $\mathrm{K}$, et al. Regulation of osteoarthritis-associated key mediators by TNFalpha and IL-10: effects of IL-10 overexpression in human synovial fibroblasts and a synovial cell line. Cell Tissue Res. 2014;357:207-223.

28. John T, Muller RD, Oberholzer A, et al. Interleukin-10 modulates pro-apoptotic effects of TNF-alpha in human articular chondrocytes in vitro. Cytokine. 2007;40:226-234. doi:10.1016/j.cyto. 2007.10.002

29. Millerand M, Sudre L, Nefla M, et al. Activation of innate immunity by 14-3-3 epsilon, a new potential alarmin in osteoarthritis. Osteoarthritis Cartilage. 2020;28:646-657. doi:10.1016/j.joca.2020.03.002

30. Minguzzi M, Cetrullo S, D'Adamo S, Silvestri Y, Flamigni F, Borzi RM. Emerging players at the intersection of chondrocyte loss of maturational arrest, oxidative stress, senescence and low-grade inflammation in osteoarthritis. Oxid Med Cell Longev. 2018;2018:3075293. doi:10.1155/ 2018/3075293

31. Chen LY, Wang Y, Terkeltaub R, Liu-Bryan R. Activation of AMPK-SIRT3 signaling is chondroprotective by preserving mitochondrial DNA integrity and function. Osteoarthritis Cartilage. 2018;26:1539-1550. doi:10.1016/j.joca.2018.07.004

32. Sun K, Jing X, Guo J, Yao X, Guo F. Mitophagy in degenerative joint diseases. Autophagy. 2020;1-11. doi:10.1080/15548627. 2020.1822097

33. Hu S, Zhang C, Ni L, et al. Stabilization of HIF-1alpha alleviates osteoarthritis via enhancing mitophagy. Cell Death Dis. 2020;11:481. doi:10.1038/s41419-020-2680-0

34. Ansari MY, Ball HC, Wase SJ, Novak K, Haqqi TM. Lysosomal dysfunction in osteoarthritis and aged cartilage triggers apoptosis in chondrocytes through BAX mediated release of Cytochrome c. Osteoarthritis Cartilage. 2020;28:S67. doi:10.1016/j.joca.2020.02.102

35. Miller RE, Scanzello CR, Malfait AM. An emerging role for Toll-like receptors at the neuroimmune interface in osteoarthritis. Semin Immunopathol. 2019;41:583-594. doi:10.10 07/s00281-019-00762-3

36. John T, Stahel PF, Morgan SJ, Schulze-Tanzil G. Impact of the complement cascade on posttraumatic cartilage inflammation and degradation. Histol Histopathol. 2007;22:781-790. doi:10.14670/ HH-22.781 
37. Silawal S, Triebel J, Bertsch T, Schulze-Tanzil G. Osteoarthritis and the complement cascade. Clin Med Insights Arthritis Musculoskelet Dis. 2018;11:1179544117751430.

38. Wang Q, Rozelle AL, Lepus CM, et al. Identification of a central role for complement in osteoarthritis. Nat Med. 2011;17:1674-1679. doi:10.1038/nm.2543

39. Favero M, El-Hadi H, Belluzzi E, et al. Infrapatellar fat pad features in osteoarthritis: a histopathological and molecular study. Rheumatol. 2017;56:1784-1793. doi:10.1093/rheumatology/kex 287

40. Zeng N, Yan ZP, Chen XY, Ni GX. Infrapatellar fat pad and knee osteoarthritis. Aging Dis. 2020;11:1317-1328. doi:10.14336/ AD.2019.1116

41. Favero M, Belluzzi E, Trisolino G, et al. Inflammatory molecules produced by meniscus and synovium in early and end-stage osteoarthritis: a coculture study. $J$ Cell Physiol. 2019; 234:11176-11187. doi:10.1002/jcp.27766

42. Belluzzi E, Macchi V, Fontanella CG, et al. Infrapatellar fat pad gene expression and protein production in patients with and without osteoarthritis. Int J Mol Sci. 2020;21:6016. doi:10.3390/ ijms21176016

43. Belluzzi E, Stocco E, Pozzuoli A, et al. Contribution of infrapatellar fat pad and synovial membrane to knee osteoarthritis pain. Biomed Res Int. 2019;2019:6390182. doi:10.1155/2019/ 6390182

44. Macchi V, Stocco E, Stecco C, et al. The infrapatellar fat pad and the synovial membrane: an anatomo-functional unit. J Anat 2018;233:146-154. doi:10.1111/joa.12820

45. Koonrungsesomboon N, Teekachunhatean S, Chansakaow S, Hanprasertpong N. Clinical efficacy and safety of yellow oil formulations 3 and 4 versus indomethacin solution in patients with symptomatic osteoarthritis of the knee: a randomized controlled trial. Evid Based Complement Altern Med. 2020; 2020:5782178.

46. Mobasheri A, Saarakkala S, Finnila M, Karsdal MA, Bay-Jensen $\mathrm{AC}$, van Spil WE. Recent advances in understanding the phenotypes of osteoarthritis. F1000Res. 2019;8:2091. doi:10.12688/ f1000research.20575.1

47. Moore RA, Derry S, Phillips CJ, McQuay HJ. Nonsteroidal anti-inflammatory drugs (NSAIDs), cyxlooxygenase-2 selective inhibitors (coxibs) and gastrointestinal harm: review of clinical trials and clinical practice. BMC Musculoskelet Dis. 2006;7:79. doi:10.1186/1471-2474-7-79

48. Vincent TL. Of mice and men: converging on a common molecular understanding of osteoarthritis. Lancet Rheumatol. 2020;2 e633-e45. doi:10.1016/S2665-9913(20)30279-4

49. Sun T, Li X, Song H, et al. MiR-146a aggravates LPS-induced inflammatory injury by targeting CXCR4 in the articular chondrocytes. Cell Physiol Biochem. 2017;44:1282-1294. doi:10.1159/000485488

50. Silawal S, Willauschus M, Schulze-Tanzil G, Gogele C, Gesslein M, Schwarz S. IL-10 could play a role in the interrelation between diabetes mellitus and osteoarthritis. Int J Mol Sci. 2019;20:768. doi:10.3390/ijms20030768

51. Mariani E, Roffi A, Cattini L, et al. Release kinetic of pro- and anti-inflammatory biomolecules from platelet-rich plasma and functional study on osteoarthritis synovial fibroblasts. Cytotherapy. 2020;22:344-353. doi:10.1016/j.jcyt.2020.02.006

52. Micheli L, Di Cesare Mannelli L, Mattoli L, et al. Intra-articular route for the system of molecules $14 \mathrm{G} 1862$ from centella asiatica: pain relieving and protective effects in a rat model of osteoarthritis. Nutrients. 2020;12:1618. doi:10.3390/nu12061618
53. Abatangelo G, Vindigni V, Avruscio G, Pandis L, Brun P. Hyaluronic acid: redefining its role. Cells. 2020;9:1743. doi:10.3390/cells9071743

54. He L, He T, Xing J, et al. Bone marrow mesenchymal stem cell-derived exosomes protect cartilage damage and relieve knee osteoarthritis pain in a rat model of osteoarthritis. Stem Cell Res Ther. 2020;11:276. doi:10.1186/s13287-020-01781-w

55. Huang Z, Kraus VB. Does lipopolysaccharide-mediated inflammation have a role in OA? Nat Rev Rheumatol. 2016;12:123-129. doi:10.1038/nrrheum.2015.158

56. Gebauer M, Saas J, Sohler F, et al. Comparison of the chondrosarcoma cell line SW1353 with primary human adult articular chondrocytes with regard to their gene expression profile and reactivity to IL-1beta. Osteoarthritis Cartilage. 2005;13: 697-708. doi:10.1016/j.joca.2005.04.004

57. Simental-Mendia M, Lozano-Sepulveda SA, Perez-Silos V, et al. Antiinflammatory and anticatabolic effect of nonanimal stabilized hyaluronic acid and mesenchymal stem cell-conditioned medium in an osteoarthritis coculture model. Mol Med Rep. 2020;21:2243-2250. doi:10.3892/mmr.2020.11004

58. Qiong J, Xia Z, Jing L, Haibin W. Synovial mesenchymal stem cells effectively alleviate osteoarthritis through promoting the proliferation and differentiation of meniscus chondrocytes. Europ Rev Med Pharmacol Sci. 2020;24:1645-1655.

59. Ragni E, Palombella S, Lopa S, et al. Innovative visualization and quantification of extracellular vesicles interaction with and incorporation in target cells in 3D microenvironments. Cells. 2020;9:1180. doi:10.3390/cells9051180

60. Belluzzi E, Olivotto E, Toso G, et al. Conditioned media from human osteoarthritic synovium induces inflammation in a synoviocyte cell line. Conn Tissue Res. 2019;60:136-145. doi:10.1080/03008207.2018.1470167

61. Haltmayer E, Ribitsch I, Gabner S, et al. Co-culture of osteochondral explants and synovial membrane as in vitro model for osteoarthritis. PLoS One. 2019;14:e0214709. doi:10.1371/journal.pone.0214709

62. Kuyinu EL, Narayanan G, Nair LS, Laurencin CT. Animal models of osteoarthritis: classification, update, and measurement of outcomes. J Orthop Surg Res. 2016;11:19.

63. Blaker CL, Clarke EC, Little CB. Using mouse models to investigate the pathophysiology, treatment, and prevention of post-traumatic osteoarthritis. J Orthop Surg Res. 2017;35:424-439. doi:10.1002/jor.23343

64. Teeple E, Jay GD, Elsaid KA, Fleming BC. Animal models of osteoarthritis: challenges of model selection and analysis. AAPS J. 2013;15:438-446. doi:10.1208/s12248-013-9454-x

65. Narez GE, Fischenich KM, Donahue TLH. Experimental animal models of post-traumatic osteoarthritis of the knee. Orthop Rev. 2020;12:8448. doi:10.4081/or.2020.8448

66. Lampropoulou-Adamidou K, Lelovas P, Karadimas EV, et al. Useful animal models for the research of osteoarthritis. Eur J Orthop Surg Traumatol. 2014;24:263-271. doi:10.1007/ s00590-013-1205-2

67. Gowler PRW, Mapp PI, Burston JJ, Shahtaheri M, Walsh DA, Chapman V. Refining surgical models of osteoarthritis in mice and rats alters pain phenotype but not joint pathology. PLoS One. 2020;15:e0239663. doi:10.1371/journal.pone.0239663

68. Adebayo OO, Holyoak DT, van der Meulen MCH. Mechanobiological mechanisms of load-induced osteoarthritis in the mouse knee. J Biomech Eng. 2019;141. doi:10.1115/ 1.4043970 
69. Fonsi M, El Amrani AI, Gervais F, Vincent P. Intra-articular hyaluronic acid and chondroitin sulfate: pharmacokinetic investigation in osteoarthritic rat models. Curr Ther Res. 2020;92:100573. doi:10.1016/j.curtheres.2019.100573

70. Blease A, Das Neves Borges P, Curtinha M, et al. Studying osteoarthritis pathogenesis in mice. Curr Protoc Mouse Biol. 2018;8:e50. doi:10.1002/cpmo.50

71. Brederson JD, Chu KL, Xu J, et al. Characterization and comparison of rat monosodium iodoacetate and medial meniscal tear models of osteoarthritic pain. J Orthop Res. 2018;36:21 09-2117. doi:10.1002/jor.23869

72. Xu J, Yan L, Yan B, Zhou L, Tong P, Shan L. Osteoarthritis pain model induced by intra-articular injection of mono-iodoacetate in rats. JoVE. 2020. doi:10.3791/60649

73. Haase T, Sunkara V, Kohl B, et al. Discerning the spatio-temporal disease patterns of surgically induced OA mouse models. PLoS One. 2019;14:e213734. doi:10.1371/journal.pone.0213734

74. Schneider T, Welker P, Licha K, Haag R, Schulze-Tanzil G. Influence of dendritic polyglycerol sulfates on knee osteoarthritis: an experimental study in the rat osteoarthritis model. $B M C$ Musculoskelet Dis. 2015;16:387. doi:10.1186/s12891-015-0844-3

75. Chang HW, Sudirman S, Yen YW, Mao CF, Ong AD, Kong ZL. Blue mussel (Mytilus edulis) water extract ameliorates inflammatory responses and oxidative stress on osteoarthritis in obese rats. J Pain Res. 2020;13:1109-1119. doi:10.2147/JPR.S244372

76. Zhong G, Liang R, Yao J, et al. Artemisinin ameliorates osteoarthritis by inhibiting the Wnt/beta-catenin signaling pathway. Cell Physiol Biochem. 2018;51:2575-2590. doi:10.1159/000495926

77. Christiansen BA, Guilak F, Lockwood KA, et al. Non-invasive mouse models of post-traumatic osteoarthritis. Osteoarthritis Cartilage. 2015;23:1627-1638. doi:10.1016/j.joca.2015.05.009

78. Bei M, Tian F, Liu N, et al. A novel rat model of patellofemoral osteoarthritis due to patella baja, or low-lying patella. Med Sci Monit. 2019;25:2702-2717.

79. Lu Y, Pei S, Hou S. Development of a novel rat model of lumbar facet joint osteoarthritis induced by persistent compressive injury. Exp Therapeut Med. 2020;20:3740-3748.

80. Aullo-Rasser G, Dousset E, Roffino S, et al. Early-stage knee OA induced by MIA and MMT compared in the murine model via histological and topographical approaches. Sci Rep. 2020; 10:15430. doi:10.1038/s41598-020-72350-7

81. Sansone V, Applefield RC, De Luca P, et al. Does a high-fat diet affect the development and progression of osteoarthritis in mice? A systematic review. Bone Joint Res. 2019;8:582-592. doi:10.1302/2046-3758.812.BJR-2019-0038.R1

82. Ernest TL, Kondrashov PE. The role of excessive body weight and meniscal instability in the progression of osteoarthritis in a rat model. Knee. 2018;25:1151-1156. doi:10.1016/j.knee.2018.07.009

83. Sun AR, Panchal SK, Friis T, et al. Obesity-associated metabolic syndrome spontaneously induces infiltration of pro-inflammatory macrophage in synovium and promotes osteoarthritis. PLoS One. 2017;12:e0183693. doi:10.1371/journal.pone.0183693

84. Javaheri B, Poulet B, Aljazzar A, et al. Stable sulforaphane protects against gait anomalies and modifies bone microarchitecture in the spontaneous STR/Ort model of osteoarthritis. Bone. 2017;103:308-317. doi:10.1016/j.bone.2017.07.028

85. Veronesi F, Della Bella E, Cepollaro S, Brogini S, Martini L, Fini M. Novel therapeutic targets in osteoarthritis: narrative review on knock-out genes involved in disease development in mouse animal models. Cytotherapy. 2016;18:593-612. doi:10.1016/j.jcyt.2016.02.001

86. Batshon G, Elayyan J, Qiq O, et al. Serum NT/CT SIRT1 ratio reflects early osteoarthritis and chondrosenescence. Ann Rheum Dis. 2020;79:1370-1380. doi:10.1136/annrheumdis-2020217072
87. Wang L, Yang M, Zhang C, Huang F. The protective effects of dehydrocostus lactone against TNF-alpha-induced degeneration of extracellular matrix (ECM) in SW1353 cells. Aging. 2020;12:17137-17149. doi:10.18632/aging.103657

88. Davidson RK, Jupp O, de Ferrars R, et al. Sulforaphane represses matrix-degrading proteases and protects cartilage from destruction in vitro and in vivo. Arthritis Rheum. 2013;65:3130-3140. doi:10.1002/art.38133

89. Wang X, Fan J, Ding X, Sun Y, Cui Z, Liu W. Tanshinone I inhibits IL-1beta-induced apoptosis, inflammation and extracellular matrix degradation in chondrocytes CHON-001 cells and attenuates murine osteoarthritis. Drug Design Dev Ther. 2019;13:3559-3568. doi:10.2147/DDDT.S216596

90. Sumantran VN, Kulkarni A, Chandwaskar R, et al. Chondroprotective potential of fruit extracts of phyllanthus emblica in osteoarthritis. Evid Based Complement Alter Med. 2008;5:329-335. doi:10.1093/ecam/nem030

91. Zhu Y, Wang Y, Zhao B, et al. Comparison of exosomes secreted by induced pluripotent stem cell-derived mesenchymal stem cells and synovial membrane-derived mesenchymal stem cells for the treatment of osteoarthritis. Stem Cell Res Ther. 2017;8:64. doi:10.1186/s13287-017-0510-9

92. Feng K, Ge Y, Chen $Z$, et al. Curcumin inhibits the PERK-eIF2alpha-CHOP pathway through promoting SIRT1 expression in oxidative stress-induced rat chondrocytes and ameliorates osteoarthritis progression in a rat model. Oxid Med Cell Longev. 2019;2019:8574386. doi:10.1155/2019/8574386

93. Sun Y, Mauerhan DR, Honeycutt PR, et al. Calcium deposition in osteoarthritic meniscus and meniscal cell culture. Arthritis Res Ther. 2010;12:R56. doi:10.1186/ar2968

94. Tarricone E, Mattiuzzo E, Belluzzi E, et al. Anti-inflammatory performance of lactose-modified chitosan and hyaluronic acid mixtures in an in vitro macrophage-mediated inflammation osteoarthritis model. Cells. 2020;9:1328. doi:10.3390/cells9061328

95. Sanchez C, Horcajada MN, Membrez Scalfo F, Ameye L, Offord E, Henrotin Y. Carnosol inhibits pro-inflammatory and catabolic mediators of cartilage breakdown in human osteoarthritic chondrocytes and mediates cross-talk between subchondral bone osteoblasts and chondrocytes. PLoS One. 2015;10: e0136118. doi:10.1371/journal.pone.0136118

96. Attur M, Krasnokutsky-Samuels S, Samuels J, Abramson SB. Prognostic biomarkers in osteoarthritis. Curr Opin Rheumatol. 2013;25:136-144. doi:10.1097/BOR.0b013e32835a9381

97. Jayakumar T, Saravana Bhavan P, Sheu JR. Molecular targets of natural products for chondroprotection in destructive joint diseases. Int $J$ Mol Sci. 2020;21:4931. doi:10.3390/ ijms 21144931

98. Chanalaris A, Doherty C, Marsden BD, et al. Suramin inhibits osteoarthritic cartilage degradation by increasing extracellular levels of chondroprotective tissue inhibitor of metalloproteinases 3. Mol Pharmacol. 2017;92:459-468. doi:10.1124/ mol.117.109397

99. van den Bosch MHJ. Inflammation in osteoarthritis: is it time to dampen the alarm(in) in this debilitating disease? Clin Exp Immunol. 2019;195:153-166. doi:10.1111/cei.13237

100. Schneider T, Welker P, Haag R, et al. Effects of dendritic polyglycerol sulfate on articular chondrocytes. Inflam Res. 2015;64:917-928. doi:10.1007/s00011-015-0875-0

101. Schulze-Tanzil G, Zreiqat H, Sabat R, et al. Interleukin-10 and articular cartilage: experimental therapeutical approaches in cartilage disorders. Curr Gene Ther. 2009;9:306-315. doi:10.2174/ 156652309788921044

102. Muller RD, John T, Kohl B, et al. IL-10 overexpression differentially affects cartilage matrix gene expression in response to TNF-alpha in human articular chondrocytes in vitro. Cytokine. 2008;44:377-385. doi:10.1016/j.cyto.2008.10.012 
103. van Helvoort EM, Popov-Celeketic J, Eijkelkamp N, et al. Canine IL4-10 fusion protein provides disease modifying activity in a canine model of $\mathrm{OA}$; an exploratory study. PLoS One. 2019;14:e0219587. doi:10.1371/journal.pone.0219587

104. Watkins LR, Chavez RA, Landry R, et al. Targeted interleukin-10 plasmid DNA therapy in the treatment of osteoarthritis: toxicology and pain efficacy assessments. Brain Behav Immun. 2020;90:155-166. doi:10.1016/j.bbi.2020.08.005

105. Liu YX, Wang GD, Wang X, Zhang YL, Zhang TL. Effects of TLR-2/NF-kappaB signaling pathway on the occurrence of degenerative knee osteoarthritis: an in vivo and in vitro study. Oncotarget. 2017;8:38602-38617. doi:10.18632/ oncotarget.16199

106. Barreto G, Manninen MKKE, Eklund K. Osteoarthritis and toll-like receptors: when innate immunity meets chondrocyte apoptosis. Biology. 2020;9:65. doi:10.3390/biology9040065

107. Liszewski MK, Java A, Schramm EC, Atkinson JP. Complement dysregulation and disease: insights from contemporary genetics. Ann Rev Pathol. 2017;12:25-52. doi:10.1146/annurev-pathol $-012615-044145$

108. Almeida M, Porter RM. Sirtuins and FoxOs in osteoporosis and osteoarthritis. Bone. 2019;121:284-292. doi:10.1016/j.bone.20 19.01.018

109. Fisch KM, Gamini R, Alvarez-Garcia O, et al. Identification of transcription factors responsible for dysregulated networks in human osteoarthritis cartilage by global gene expression analysis. Osteoarthritis Cartilage. 2018;26:1531-1538. doi:10.10 16/j.joca.2018.07.012

110. Guo JY, Li F, Wen YB, et al. Melatonin inhibits Sirt1-dependent NAMPT and NFAT5 signaling in chondrocytes to attenuate osteoarthritis. Oncotarget. 2017;8:55967-55983. doi:10.18632/ oncotarget. 18356

111. Hossain FM, Hong Y, Jin Y, Choi J, Hong Y. Physiological and pathological role of circadian hormones in osteoarthritis: dose-dependent or time-dependent? J Clin Med. 2019;8:1415. doi:10.3390/jcm8091415

112. Pal B, Endisha H, Zhang Y, Kapoor M. mTOR: a potential therapeutic target in osteoarthritis? Drugs $R$ D. 2015;15:27-36. doi:10.1007/s40268-015-0082-z

113. Sun K, Luo J, Guo J, Yao X, Jing X, Guo F. The PI3K/AKT/ mTOR signaling pathway in osteoarthritis: a narrative review. Osteoarthritis Cartilage. 2020;28:400-409. doi:10.1016/j. joca.2020.02.027

114. Vasheghani F, Zhang Y, Li YH, et al. PPARgamma deficiency results in severe, accelerated osteoarthritis associated with aberrant mTOR signalling in the articular cartilage. Ann Rheum Dis. 2015;74:569-578. doi:10.1136/annrheumdis-2014-205743

115. Khan NM, Haseeb A, Ansari MY, Devarapalli P, Haynie S, Haqqi TM. Wogonin, a plant derived small molecule, exerts potent anti-inflammatory and chondroprotective effects through the activation of ROS/ERK/Nrf2 signaling pathways in human Osteoarthritis chondrocytes. Free Radic Biol Med. 2017;106:288-301. doi:10.1016/j.freeradbiomed.2017.02.041

116. Zhao X, Petursson F, Viollet B, Lotz M, Terkeltaub R, Liu-Bryan R. Peroxisome proliferator-activated receptor gamma coactivator 1alpha and FoxO3A mediate chondroprotection by AMP-activated protein kinase. Arthritis Rheumatol. 2014;66:3073-3082. doi:10. 1002/art.38791

117. Li H, Ding X, Terkeltaub R, et al. Exploration of metformin as novel therapy for osteoarthritis: preventing cartilage degeneration and reducing pain behavior. Arthritis Res Ther. 2020;22:34. doi:10.1186/s13075-020-2129-y
118. Wang Y, Fan X, Xing L, Tian F. Wnt signaling: a promising target for osteoarthritis therapy. Cell Commun Signal. 2019;17:97. doi:10.1186/s12964-019-0411-x

119. Lane NE. Inhibition of wingless-related integration site (Wnt) signalling may treat osteoarthritis of the knee. Trans Am Clin Climatol Assoc. 2020;131:55-64.

120. Chen D, Kim DJ, Shen J, Zou Z, O'Keefe RJ. Runx2 plays a central role in Osteoarthritis development. J Orthop Transl. 2020;23:132-139.

121. Gao H, Gui J, Wang L, et al. Aquaporin 1 contributes to chondrocyte apoptosis in a rat model of osteoarthritis. Int J Mol Sci. 2016;38:1752-1758.

122. Shin HJ, Park H, Shin N, et al. p66she siRNA nanoparticles ameliorate chondrocytic mitochondrial dysfunction in osteoarthritis. Int J Nanomedicine. 2020;15:2379-2390. doi:10.21 47/IJN.S234198

123. Shin HJ, Park H, Shin N, et al. Pink1-mediated chondrocytic mitophagy contributes to cartilage degeneration in osteoarthritis. J Clin Med. 2019;8:1849. doi:10.3390/jcm8111849

124. Ansari MY, Khan NM, Ahmad I, Haqqi TM. Parkin clearance of dysfunctional mitochondria regulates ROS levels and increases survival of human chondrocytes. Osteoarthritis Cartilage. 2018;26:1087-1097. doi:10.1016/j.joca.2017.07.020

125. Jimi E, Fei H, Nakatomi C. NF-kappaB signaling regulates physiological and pathological chondrogenesis. Int $J \mathrm{Mol}$ Sci. 2019;20. doi:10.3390/ijms20246275

126. Mariano A, Di Sotto A, Leopizzi M, et al. Antiarthritic effects of a root extract from harpagophytum procumbens DC: novel insights into the molecular mechanisms and possible bioactive phytochemicals. Nutrients. 2020;12:2545. doi:10.3390/nu12 092545

127. Ansaripour S, Dehghan M. Efficacy of some herbal medicines in osteoarthritis with a focus on topical agents: a systematic review. Curr Pharm Des. 2020;26:2676-2681. doi:10.2174/138161282 6666200429013728

128. Lee D, Ju MK, Kim H. Commiphora extract mixture ameliorates monosodium iodoacetate-induced osteoarthritis. Nutrients. 2020;12.

129. Chen $\mathrm{Z}, \mathrm{Wu} \mathrm{G}$, Zheng R. A systematic pharmacology and in vitro study to identify the role of the active compounds of Achyranthes bidentata in the treatment of osteoarthritis. Med Sci Monit. 2020;26:e925545. doi:10.12659/MSM.925545

130. D'Adamo S, Cetrullo S, Panichi V, Mariani E, Flamigni F, Borzi RM. Nutraceutical activity in osteoarthritis biology: a focus on the nutrigenomic role. Cells. 2020;9:1232. doi:10.3390/cells 9051232

131. Mead MN. Nutrigenomics: the genome-food interface. Environ Health Perspect. 2007;115:A582-A589. doi:10.1289/ehp.115-a582

132. Karthikeyan A, Senthil N, Min T. Nanocurcumin: a promising candidate for therapeutic applications. Front Pharmacol. 2020;11:487. doi:10.3389/fphar.2020.00487

133. Zhao H, Zhang T, Xia C, et al. Berberine ameliorates cartilage degeneration in interleukin-1beta-stimulated rat chondrocytes and in a rat model of osteoarthritis via Akt signalling. J Cell Mol Med. 2014;18:283-292. doi:10.1111/jcmm.12186

134. Zheng W, Zhang H, Jin Y, et al. Butein inhibits IL-1beta-induced inflammatory response in human osteoarthritis chondrocytes and slows the progression of osteoarthritis in mice. Int Immunopharmacol. 2017;42:1-10. doi:10.1016/j.intimp.2016.11.009

135. Ansari MY, Ahmad N, Haqqi TM. Butein activates autophagy through AMPK/TSC2/ULK1/mTOR pathway to inhibit IL-6 expression in IL-1beta stimulated human chondrocytes. Cell Physiol Biochem. 2018;49:932-946. doi:10.1159/000493225 
136. Schwager J, Richard N, Fowler A, Seifert N, Raederstorff D. Carnosol and related substances modulate chemokine and cytokine production in macrophages and chondrocytes. Molecules. 2016;21:465. doi:10.3390/molecules21040465

137. Schulze-Tanzil G, Mobasheri A, Sendzik J, John T, Shakibaei M. Effects of curcumin (diferuloylmethane) on nuclear factor kappaB signaling in interleukin-1betastimulated chondrocytes. Ann N Y Acad Sci. 2004; 1030:578-586. doi:10.1196/annals.1329.067

138. Scazzocchio B, Minghetti L, D'Archivio M. Interaction between gut microbiota and curcumin: a new key of understanding for the health effects of curcumin. Nutrients. 2020;12:2499. doi:10.3390/ nu12092499

139. Zhang G, Cao J, Yang E, et al. Curcumin improves age-related and surgically induced osteoarthritis by promoting autophagy in mice. Biosci Rep. 2018;38.

140. Shirinsky IV, Kalinovskaya NY, Filatova K, Shirinsky VS. Pleiotropic effects of Comarum palustre 1. in patients with osteoarthritis and diabetes mellitus with high comorbidity burden: an exploratory study. Altern Ther Health Med. 2020.

141. Zhang X, Yao J, Wu Z, et al. Chondroprotective and antiarthritic effects of Daphnetin used in vitro and in vivo osteoarthritis models. Life Sci. 2020;240:116857. doi:10.1016/j.lfs.2019.116857

142. Tanideh N, Ashkani-Esfahani S, Sadeghi F, et al. The protective effects of grape seed oil on induced osteoarthritis of the knee in male rat models. J Orthop Surg Res. 2020;15:400. doi:10.1186/ s13018-020-01932-y

143. Bai H, Zhang Z, Li Y, et al. L-theanine reduced the development of knee osteoarthritis in rats via its anti-inflammation and anti-matrix degradation actions: in vivo and in vitro study. Nutrients. 2020;12:1988. doi:10.3390/nu12071988

144. Leong DJ, Choudhury M, Hanstein R, et al. Green tea polyphenol treatment is chondroprotective, anti-inflammatory and palliative in a mouse post-traumatic osteoarthritis model. Arthritis Res Ther. 2014;16:508. doi:10.1186/s13075-014-0508-y

145. Schulze-Tanzil G, Hansen C, Shakibaei M. [Effect of a Harpagophytum procumbens DC extract on matrix metalloproteinases in human chondrocytes in vitro]. ArzneimittelForschung. 2004;54:213-220. doi:10.1055/s-0031-1296962. German.

146. Zu Y, Mu Y, Li Q, Zhang ST, Yan HJ. Icariin alleviates osteoarthritis by inhibiting NLRP3-mediated pyroptosis. J Orthop Surg Res. 2019;14:307. doi:10.1186/s13018-019-1307-6

147. Ji B, Zhang Z, Guo W, et al. Isoliquiritigenin blunts osteoarthritis by inhibition of bone resorption and angiogenesis in subchondral bone. Sci Rep. 2018;8:1721. doi:10.1038/s41598018-19162-y

148. Alam W, Khan H, Shah MA, Cauli O, Saso L. Kaempferol as a dietary anti-inflammatory agent: current therapeutic standing. Molecules. 2020;25:4073. doi:10.3390/ molecules 25184073

149. Estakhri F, Panjehshahin MR, Tanideh N, et al. The effect of kaempferol and apigenin on allogenic synovial membrane-derived stem cells therapy in knee osteoarthritic male rats. Knee. 2020;27:817-832. doi:10.1016/j.knee.2020.03.005

150. Park MH, Jung JC, Hill S, et al. FlexPro MD(R), a combination of krill oil, astaxanthin and hyaluronic acid, reduces pain behavior and inhibits inflammatory response in monosodium iodoacetate-induced osteoarthritis in rats. Nutrients. 2020;12:956. doi:10.3390/ nu12040956

151. Chin KY, Pang KL. Therapeutic effects of olive and its derivatives on osteoarthritis: from bench to bedside. Nutrients. 2017;9:1060. doi:10.3390/nu9101060
152. Yi H, Zhang W, Cui ZM, et al. Resveratrol alleviates the interleukin-1beta-induced chondrocytes injury through the NF-kappaB signaling pathway. J Orthop Surg Res. 2020;15:424. doi:10.1186/s13018-020-01944-8

153. Wei Y, Jia J, Jin X, Tong W, Tian H. Resveratrol ameliorates inflammatory damage and protects against osteoarthritis in a rat model of osteoarthritis. Mol Med Rep. 2018;17:1493-1498. doi: $10.3892 / \mathrm{mmr} .2017 .8036$

154. Schulze-Tanzil G, de Souza P, Behnke B, Klingelhoefer S, Scheid A, Shakibaei M. Effects of the antirheumatic remedy hox alpha-a new stinging nettle leaf extract-on matrix metalloproteinases in human chondrocytes in vitro. Histol Histopathol. 2002;17:477-485. doi:10.14670/HH-17.477

155. Kalamegam G, Alfakeeh SM, Bahmaid AO, et al. In vitro evaluation of the anti-inflammatory effects of thymoquinone in osteoarthritis and in silico analysis of inter-related pathways in age-related degenerative diseases. Front Cell Dev Biol. 2020;8:646. doi:10.3389/fcell.2020.00646

156. Wang C, Gao Y, Zhang Z, et al. Ursolic acid protects chondrocytes, exhibits anti-inflammatory properties via regulation of the NF-kappaB/NLRP3 inflammasome pathway and ameliorates osteoarthritis. Biomed Pharmacother. 2020;130:110568. doi:10. 1016/j.biopha.2020.110568

157. Smith JF, Starr EG, Goodman MA, et al. Topical application of wogonin provides a novel treatment of knee osteoarthritis. Front Physiol. 2020;11:80. doi:10.3389/fphys.2020.00080

158. Rades N, Licha K, Haag R. Dendritic polyglycerol sulfate for therapy and diagnostics. Polymers. 2018;10:595. doi:10.3390/ polym 10060595

159. Reimann S, Schneider T, Welker P, et al. Dendritic polyglycerol anions for the selective targeting of native and inflamed articular cartilage. J Mater Chem B. 2017;5:4754-4767. doi:10.1039/ C7TB00618G

160. Hu B, Gao F, Li C, et al. Rhein laden $\mathrm{pH}$-responsive polymeric nanoparticles for treatment of osteoarthritis. AMB Express. 2020;10:158. doi:10.1186/s13568-020-01095-3

161. Zhang M, Tang J, Shan H, et al. p66Shc mediates mitochondrial dysfunction dependent on PKC activation in airway epithelial cells induced by cigarette smoke. Oxid Med Cell Longev. 2018;2018:5837123. doi:10.1155/2018/5837123

162. Nasi S, Ehirchiou D, Chatzianastasiou A, et al. The protective role of the 3-mercaptopyruvate sulfurtransferase (3-MST)hydrogen sulfide (H2S) pathway against experimental osteoarthritis. Arthritis Res Ther. 2020;22:49. doi:10.1186/ s13075-020-02147-6

163. Moreau M, Rialland P, Pelletier JP, et al. Tiludronate treatment improves structural changes and symptoms of osteoarthritis in the canine anterior cruciate ligament model. Arthritis Res Ther. 2011;13:R98. doi:10.1186/ar3373

164. Bongartz T, Sutton AJ, Sweeting MJ, Buchan I, Matteson EL, Montori V. Anti-TNF antibody therapy in rheumatoid arthritis and the risk of serious infections and malignancies: systematic review and meta-analysis of rare harmful effects in randomized controlled trials. JAMA. 2006;295:2275-2285. doi:10.1001/jama.295. 19.2275

165. Wang $\mathrm{W}, \mathrm{Lin} \mathrm{X}, \mathrm{Xu} \mathrm{H}$, et al. Attenuated joint tissue damage associated with improved synovial lymphatic function following treatment with bortezomib in a mouse model of experimental posttraumatic osteoarthritis. Arthritis Rheumatol. 2019;71:24 4-257. doi:10.1002/art.40696

166. Badendick J, Godkin O, Kohl B, et al. Macroscopical, histological, and in vitro characterization of nonosteoarthritic versus osteoarthritic hip joint cartilage. Clin Med Insights Arthritis Musculoskelet Disord. 2016;9:65-74. 
167. Nazli SA, Loeser RF, Chubinskaya S, Willey JS, Yammani RR. High fat-diet and saturated fatty acid palmitate inhibits IGF-1 function in chondrocytes. Osteoarthritis Cartilage. 2017; 25:1516-1521. doi:10.1016/j.joca.2017.05.011

168. Wei FY, Lee JK, Wei L, Qu F, Zhang JZ. Correlation of insulin-like growth factor 1 and osteoarthritic cartilage degradation: a spontaneous osteoarthritis in guinea-pig. Eur Rev Med Pharmacol Sci. 2017;21:4493-4500.

169. Mori Y, Saito T, Chang SH, et al. Identification of fibroblast growth factor-18 as a molecule to protect adult articular cartilage by gene expression profiling. $J$ Biol Chem. 2014;28 9:10192-10200. doi:10.1074/jbc.M113.524090

170. Roman-Blas JA, Castaneda S, Largo RHerrero-Beaumont G, HerreroBeaumont G. Osteoarthritis associated with estrogen deficiency. Arthritis Res Ther. 2009;11:241. doi:10.1186/ar2791

171. Zou Y, Liu Q, Guo P, Huang Y, Ye Z, Hu J. Antichondrocyte apoptosis effect of genistein in treating inflammation-induced osteoarthritis. Mol Med Rep. 2020;22:2032-2042. doi:10.3892/ mmr.2020.11254

172. Que Q, Guo X, Zhan L, et al. The GLP-1 agonist, liraglutide, ameliorates inflammation through the activation of the PKA/ CREB pathway in a rat model of knee osteoarthritis. J Inflamm. 2019;16:13. doi:10.1186/s12950-019-0218-y

173. Mei J, Sun J, Wu J, Zheng X. Liraglutide suppresses TNF-alphainduced degradation of extracellular matrix in human chondrocytes: a therapeutic implication in osteoarthritis. Am J Transl Res. 2019;11:4800-4808.

174. Roux CH, Pisani DF, Gillet P, et al. Oxytocin controls chondrogenesis and correlates with osteoarthritis. Int $J \mathrm{Mol} S \mathrm{Sci}$. 2020;21:3966. doi:10.3390/ijms21113966

175. Wang FS, Kuo CW, Ko JY, et al. Irisin mitigates oxidative stress, chondrocyte dysfunction and osteoarthritis development through regulating mitochondrial integrity and autophagy. Antioxidants. 2020;9:810. doi:10.3390/antiox9090810

176. Mohan G, Magnitsky S, Melkus G, et al. Kartogenin treatment prevented joint degeneration in a rodent model of osteoarthritis: a pilot study. J Orthop Res. 2016;34:1780-1789. doi:10.1002/ jor.23197

177. Favazzo LJ, Hendesi H, Villani DA, et al. The gut microbiome-joint connection: implications in osteoarthritis. Curr Opin Rheumatol. 2020;32:92-101. doi:10.1097/BOR.00000000 00000681

178. Barry F. MSC therapy for osteoarthritis: an unfinished story. J Orthop Res. 2019;37:1229-1235. doi:10.1002/jor.24343

179. Ip HL, Nath DK, Sawleh SH, Kabir MH, Jahan N. Regenerative medicine for knee osteoarthritis - the efficacy and safety of intra-articular platelet-rich plasma and mesenchymal stem cells injections: a literature review. Cureus. 2020;12:e10575. doi:10. $7759 /$ cureus. 10575

180. Kuroda Y, Matsumoto T, Hayashi S, et al. Intra-articular autologous uncultured adipose-derived stromal cell transplantation inhibited the progression of cartilage degeneration. $J$ Orthop Res. 2019;37:1376-1386. doi:10.1002/jor.24174

181. Mei L, Shen B, Ling P, et al. Culture-expanded allogenic adipose tissue-derived stem cells attenuate cartilage degeneration in an experimental rat osteoarthritis model. PLoS One. 2017;12: e0176107. doi:10.1371/journal.pone.0176107

182. Chiang ER, Ma HL, Wang JP, Liu CL, Chen TH, Hung SC. Allogeneic mesenchymal stem cells in combination with hyaluronic acid for the treatment of osteoarthritis in rabbits. PLoS One. 2016;11:e0149835. doi:10.1371/journal.pone.0149835

183. Neybecker P, Henrionnet C, Pape E, et al. In vitro and in vivo potentialities for cartilage repair from human advanced knee osteoarthritis synovial fluid-derived mesenchymal stem cells. Stem Cell Res Ther. 2018;9:329. doi:10.1186/s13287-0181071-2
184. Topoluk N, Steckbeck K, Siatkowski S, Burnikel B, Tokish J, Mercuri J. Amniotic mesenchymal stem cells mitigate osteoarthritis progression in a synovial macrophage-mediated in vitro explant coculture model. $J$ Tissue Eng Reg Med. 2018;12:1097-1110. doi:10.1002/term.2610

185. Lapuente JP, Dos-Anjos SBlazquez-Martinez A. Intra-articular infiltration of adipose-derived stromal vascular fraction cells slows the clinical progression of moderate-severe knee osteoarthritis: hypothesis on the regulatory role of intra-articular adipose tissue. J Orthop Surg Res. 2020;15:137. doi:10.1186/s13018-020-01664-z

186. Kim H, Lee BK. Anti-inflammatory effect of adipose-derived stromal vascular fraction on osteoarthritic temporomandibular joint synoviocytes. J Tissue Eng Reg Med. 2020;17:351-362. doi:10.1007/s13770-020-00268-2

187. Ringe J, Hemmati-Sadeghi S, Frohlich K, et al. CCL25supplemented hyaluronic acid attenuates cartilage degeneration in a guinea pig model of knee osteoarthritis. J Orthop Res. 2019;37:1723-1729. doi:10.1002/jor.24312

188. Coutinho de Almeida R, Mahfouz A, Mei H, et al. Identification and characterization of two consistent osteoarthritis subtypes by transcriptome and clinical data integration. Rheumatol. 2020. doi:10.1093/rheumatology/keaa391

189. Hou SM, Chen PC, Lin CM, Fang ML, Chi MC, Liu JF. CXCL1 contributes to IL-6 expression in osteoarthritis and rheumatoid arthritis synovial fibroblasts by CXCR2, c-Raf, MAPK, and AP-1 pathway. Arthritis Res Ther. 2020;22:251. doi:10.1186/s13075-020-02331-8

190. Xin F, Wang H, Yuan F, Ding Y. Platelet-rich plasma combined with alendronate reduces pain and inflammation in induced osteoarthritis in rats by inhibiting the nuclear factor-kappa B signaling pathway. Biomed Res Int. 2020;2020:8070295. doi: $10.1155 / 2020 / 8070295$

191. Muller S, Acevedo L, Wang X, et al. Notochordal cell conditioned medium (NCCM) regenerates end-stage human osteoarthritic articular chondrocytes and promotes a healthy phenotype. Arthritis Res Ther. 2016;18:125. doi:10.1186/s13075-016-1026-x

192. Cosenza S, Ruiz M, Toupet K, Jorgensen C, Noel D. Mesenchymal stem cells derived exosomes and microparticles protect cartilage and bone from degradation in osteoarthritis. Sci Rep. 2017;7:16214. doi:10.1038/s41598-017-15376-8

193. Zhao C, Chen JY, Peng WM, Yuan B, Bi Q, Xu YJ. Exosomes from adipose-derived stem cells promote chondrogenesis and suppress inflammation by upregulating miR145 and miR221. Mol Med Rep. 2020;21:1881-1889. doi:10.3892/mmr.2020.10982

194. Mendt M, Rezvani K, Shpall E. Mesenchymal stem cell-derived exosomes for clinical use. Bone Marrow Transplant. 2019; 54:789-792. doi:10.1038/s41409-019-0616-z

195. Otahal A, Kramer K, Kuten-Pella O, et al. Characterization and chondroprotective effects of extracellular vesicles from plasmaand serum-based autologous blood-derived products for osteoarthritis therapy. Front Bioeng Biotechnol. 2020;8:584050. doi:10.3389/fbioe.2020.584050

196. Tao SC, Yuan T, Zhang YL, Yin WJ, Guo SC, Zhang CQ. Exosomes derived from miR-140-5p-overexpressing human synovial mesenchymal stem cells enhance cartilage tissue regeneration and prevent osteoarthritis of the knee in a rat model. Theranostics. 2017;7:180-195. doi:10.7150/thno.17133

197. Wang Y, Yu D, Liu Z, et al. Exosomes from embryonic mesenchymal stem cells alleviate osteoarthritis through balancing synthesis and degradation of cartilage extracellular matrix. Stem Cell Res Ther. 2017;8:189. doi:10.1186/s13287-017-0632-0

198. Ragni E, Perucca Orfei C, De Luca P, et al. miR-22-5p and miR-29a-5p are reliable reference genes for analyzing extracellular vesicle-associated miRNAs in adipose-derived mesenchymal stem cells and are stable under inflammatory priming mimicking osteoarthritis condition. Stem Cell Rev Rep. 2019;15:743-754. doi:10.1007/s12015-019-09899-y 
199. Kosinska MK, Ludwig TE, Liebisch G, et al. Articular joint lubricants during osteoarthritis and rheumatoid arthritis display altered levels and molecular species. PLoS One. 2015;10: e0125192. doi:10.1371/journal.pone.0125192

200. Migliore A, Procopio S. Effectiveness and utility of hyaluronic acid in osteoarthritis. Clin Cases Miner Bone Metab. 2015;12:31-33. doi:10.11138/ccmbm/2015.12.1.031

201. Cicognani M, Rossi S, Vecchi G, Giori AM, Ferrari F. DoEassisted development of a novel glycosaminoglycan-based injectable formulation for viscosupplementation. Pharmaceutics. 2020;12:681. doi:10.3390/pharmaceutics12070681

202. Oliveira MZ, Albano MB, Stirma GA, Namba MM, Vidigal L, Cunha L. Intra-articular viscosupplementation of hyaluronic acids in an experimental osteoarthritis model. Rev Bras Ortop. 2018;53:293-299. doi:10.1016/j.rbo.2017.04.014

203. Gupta RC, Lall R, Srivastava A, Sinha A. Hyaluronic acid: molecular mechanisms and therapeutic trajectory. Front Veterinary Sci. 2019;6:192.

204. Knudson W, Ishizuka S, Terabe K, Askew EB, Knudson CB. The pericellular hyaluronan of articular chondrocytes. Matrix Biol. 2019;78-79:32-46. doi:10.1016/j.matbio.2018.02.005

205. Moreland LW. Intra-articular hyaluronan (hyaluronic acid) and hylans for the treatment of osteoarthritis: mechanisms of action. Arthritis Res Ther. 2003;5:54-67. doi:10.1186/ar623

206. Vitanzo PC, Sennett BJ. Hyaluronans: is clinical effectiveness dependent on molecular weight? Am J Orthop. 2006;35:421-428.

207. Lisignoli G, Grassi F, Zini N, et al. Anti-Fas-induced apoptosis in chondrocytes reduced by hyaluronan: evidence for CD44 and CD54 (intercellular adhesion molecule 1) involvement. Arthritis Rheum. 2001;44:1800-1807. doi:10.1002/1529-0131(200108) 44:8<1800::AID-ART317>3.0.CO;2-1

208. Webb D, Naidoo P. Viscosupplementation for knee osteoarthritis: a focus on Hylan G-F 20. Orthop Res Rev. 2018;10:73-81. doi:10.2147/ORR.S174649

209. Liu Z, Lin W, Fan Y, Kampf N, Wang Y, Klein J. Effects of hyaluronan molecular weight on the lubrication of cartilage-emulating boundary layers. Biomacromolecules. 2020;21:4345-4354. doi:10.1021/acs.biomac.0c01151

210. Bahrami MH, Raeissadat SA, Cheraghi M, Rahimi-Dehgolan S, Ebrahimpour A. Efficacy of single high-molecular-weight versus triple low-molecular-weight hyaluronic acid intra-articular injection among knee osteoarthritis patients. BMC Musculoskelet Dis. 2020;21:550. doi:10.1186/s12891-020-03577-8

211. Concoff A, Sancheti P, Niazi F, Shaw P, Rosen J. The efficacy of multiple versus single hyaluronic acid injections: a systematic review and meta-analysis. BMC Musculoskelet Dis. 2017;18:542. doi:10.1186/s12891-017-1897-2

212. Ong KL, Runa M, Lau E, Altman R. Is intra-articular injection of synvisc associated with a delay to knee arthroplasty in patients with knee osteoarthritis? Cartilage. 2019;10:423-431. doi:10. $1177 / 1947603518775792$

213. Ogata T, Ideno Y, Akai M, et al. Effects of glucosamine in patients with osteoarthritis of the knee: a systematic review and meta-analysis. Clin Rheumatol. 2018;37:2479-2487. doi:10.1007/ s10067-018-4106-2

214. Ruan MZ, Erez A, Guse K, et al. Proteoglycan 4 expression protects against the development of osteoarthritis. Sci Transl Med. 2013;5:176ra34. doi:10.1126/scitranslmed.3005409

215. Chavez RD, Sohn P, Serra R, Jabbari E. Prg4 prevents osteoarthritis induced by dominant-negative interference of TGF-ss signaling in mice. PLoS One. 2019;14:e0210601. doi:10.1371/ journal.pone. 0210601
216. Stone A, Grol MW, Ruan MZC, et al. Combinatorial Prg4 and Il-1ra gene therapy protects against hyperalgesia and cartilage degeneration in post-traumatic osteoarthritis. Hum Gene Ther. 2019;30:225-235. doi:10.1089/hum.2018.106

217. Watson Levings RS, Smith AD, Broome TA, et al. Selfcomplementary adeno-associated virus-mediated interleukin-1 receptor antagonist gene delivery for the treatment of osteoarthritis: test of efficacy in an equine model. Hum Gene Ther Clin Dev. 2018;29:101-112. doi:10.1089/humc.2017.143

218. Tan Timur U, Caron M, van den Akker G, et al. Increased TGF-beta and BMP levels and improved chondrocyte-specific marker expression in vitro under cartilage-specific physiological osmolarity. Int J Mol Sci. 2019;20:795. doi:10.3390/ijms20040795

219. Eltawil NM, Ahmed S, Chan LH, Simpson A, Hall AC. Chondroprotection in models of cartilage injury by raising the temperature and osmolarity of irrigation solutions. Cartilage. 2018;9:313-320. doi:10.1177/1947603516688511

220. Mang T, Lindemann S, Gigout A. Increasing the medium osmolarity reduces the inflammatory status of human OA chondrocytes and increases their responsiveness to GDF-5. Int $\mathrm{J} \mathrm{Mol} \mathrm{Sci}$. 2020;21:531. doi:10.3390/ijms21020531

221. Xiong F, Qin Z, Chen H, et al. pH-responsive and hyaluronic acid-functionalized metal-organic frameworks for therapy of osteoarthritis. J Nanobiotechnol. 2020;18:139. doi:10.1186/ s12951-020-00694-3

222. Wang AT, Zhang QF, Wang NX, et al. Cocktail of hyaluronic acid and human amniotic mesenchymal cells effectively repairs cartilage injuries in sodium iodoacetate-induced osteoarthritis rats. Front Bioeng Biotechnol. 2020;8:87. doi:10.3389/ fbioe. 2020.00087

223. Luderitz L, Dehne T, Sittinger M, Ringe J. Dose-dependent effect of mesenchymal stromal cell recruiting chemokine CCL25 on porcine tissue-engineered healthy and osteoarthritic cartilage. Int J Mol Sci. 2018;20:52. doi:10.3390/ijms20010052

224. Rice SJ, Beier F, Young DA, Loughlin J. Interplay between genetics and epigenetics in osteoarthritis. Nat Rev. 2020;16:268-281. doi:10.1038/s41584-020-0407-3

225. Shen J, Abu-Amer Y, O'Keefe RJ, McAlinden A. Inflammation and epigenetic regulation in osteoarthritis. Conn Tissue Res. 2017;58:49-63. doi:10.1080/03008207.2016.1208655

226. Kim H, Kang D, Cho Y, Kim JH. Epigenetic regulation of chondrocyte catabolism and anabolism in osteoarthritis. Mol Cells. 2015;38:677-684. doi:10.14348/molcells.2015.0200

227. Duan L, Liang Y, Xu X, Xiao Y, Wang D. Recent progress on the role of miR-140 in cartilage matrix remodelling and its implications for osteoarthritis treatment. Arthritis Res Ther. 2020;22:194. doi:10.1186/s13075-020-02290-0

228. Guo Y, Min Z, Jiang C, et al. Downregulation of HS6ST2 by miR-23b-3p enhances matrix degradation through p38 MAPK pathway in osteoarthritis. Cell Death Dis. 2018;9:699. doi:10.1038/s41419-018-0729-0

229. Mao T, He C, Wu H, Yang B, Li X. Silencing lncRNA HOTAIR declines synovial inflammation and synoviocyte proliferation and promotes synoviocyte apoptosis in osteoarthritis rats by inhibiting Wnt/beta-catenin signaling pathway. Cell Cycle. 2019;18:3189-3205. doi:10.1080/15384101.2019.1671716

230. Cheng M, Wang Y. Downregulation of HMGB1 by miR-103a-3p promotes cell proliferation, alleviates apoptosis and in flammation in a cell model of osteoarthritis. Iran J Biotechnol. 2020;18: e2255. doi:10.30498/IJB.2020.129470.2255

231. Chen X, Shi Y, Xue P, Ma X, Li J, Zhang J. Mesenchymal stem cell-derived exosomal microRNA-136-5p inhibits chondrocyte degeneration in traumatic osteoarthritis by targeting ELF3. Arthritis Res Ther. 2020;22:256. doi:10.1186/s13075-020-02325-6 
232. Zhang Q, Qiao X, Xia W. CircSERPINE2 weakens IL-1betacaused apoptosis and extracellular matrix degradation of chondrocytes by regulating miR-495/TGFBR2 axis. Biosci Rep. 2020;40. doi:10.1042/BSR20201601

233. Li Z, Wang J, Yang J. TUG1 knockdown promoted viability and inhibited apoptosis and cartilage ECM degradation in chondrocytes via the miR-17-5p/FUT1 pathway in osteoarthritis. Exp Ther Med. 2020;20:154. doi:10.3892/etm.2020.9283
234. Zhou Z, Ma J, Lu J, Chen A, Zhu L. Circular RNA CircCDH13 contributes to the pathogenesis of osteoarthritis via CircCDH13/ miR-296-3p/PTEN axis. J Cell Physiol. 2020. doi:10.1002/jcp.30091

\section{Publish your work in this journal}

The Journal of Experimental Pharmacology is an international, peerreviewed, open access journal publishing original research, reports, reviews and commentaries on all areas of laboratory and experimental pharmacology. The manuscript management system is completely online and includes a very quick and fair peer-review system. Visit http://www.dovepress.com/testimonials.php to read real quotes from published authors.

Submit your manuscript here: https://www.dovepress.com/journal-of-experimental-pharmacology-journal 